Research Article

\title{
Joint Amplitude and Frequency Demodulation Analysis Based on Variational Mode Decomposition for Multifault Diagnosis of a Multistage Reducer
}

\author{
Feng Li, ${ }^{1,2}$ Xinyu Pang, ${ }^{1,2}$ and Zhaojian Yang $\mathbb{C}^{1,2}$ \\ ${ }^{1}$ College of Mechanical Engineering, Taiyuan University of Technology, Taiyuan 030024, China \\ ${ }^{2}$ Shanxi Key Laboratory of Fully Mechanized Coal Mining Equipment, Taiyuan 030024, China \\ Correspondence should be addressed to Zhaojian Yang; yangzhaojian@tyut.edu.cn
}

Received 26 February 2018; Revised 13 May 2018; Accepted 6 August 2018; Published 9 October 2018

Academic Editor: Luca Z. Fragonara

Copyright (C) 2018 Feng Li et al. This is an open access article distributed under the Creative Commons Attribution License, which permits unrestricted use, distribution, and reproduction in any medium, provided the original work is properly cited.

\begin{abstract}
Multistage reducer vibration signals have complicated spectral structures owing to the amplitude and frequency modulations of gear damage-induced vibrations and the multiplicative amplitude modulation effect caused by time-varying vibration transfer paths (in the case of local gear damage) when the multistage reducer contains both planetary and spur gears. Moreover, the difference between the vibration energies of these gears increases the difficulty of fault feature extraction when multiple failures occur in the reducer. As the meshing frequency of each gear group often varies significantly, variational mode decomposition can be performed to decompose the vibration signal according to frequency, enabling separation of the vibration signals of the spur and planetary gears. The common fault features of these gears can be extracted from the spectrum of the amplitude demodulation envelope. To verify the effectiveness of this method, we first analyzed a simulation signal, and then utilized the experimental signals from a laboratory multistage reducer for verification. In the multistage reducer simulation, we considered the amplitude and frequency modulation of the gear damage and transfer paths. In the experimental verification, we processed local faults (broken teeth) and uniform faults (uniform wear) on the sun gear and the spur gear of the planetary gear separately.
\end{abstract}

\section{Introduction}

Multistage reducers are used extensively as key components in industry because of their compact structures, large transmission ratios, strong carrying capacities, stable operation, and high efficiencies $[1,2]$. Further, as single-stage reducers can no longer meet the requirements of many types of engineering machinery, automobiles, aircraft, ships, and other equipment, multistage gear drives with multistage reducers are now essential. However, because multispeed reducers often contain multiple spur, planetary gears, or a combination thereof, the housing vibration signals of the gearbox are more complex than that of single-stage reducers, especially when planetary gears are involved [3]. Further, as reducer failure may lead to mechanical failure or even accidents, reducer fault diagnosis is very important.

The structure of a spur gear is simple, and the vibration signal mainly includes the rotation frequency, meshing frequency, and harmonic component. A planetary gear usually consists of a sun gear, several planet wheels, a ring gear, and a planet carrier. Usually, the ring gear is stationary, the sun gear rotates, and the planet gears not only revolve with the planet carrier, but also spin around their own centers. Because of the complicated internal dynamics and external environmental excitation, the vibration signals of planetary gears exhibit complex time-varying modulation, which leads to fault feature extraction difficulty [1]. In practice, to achieve more effective transmission, a planetary gear is often used with a spur gear, which makes the multistage reducer vibration signal more complex. When many gear faults occur in a multistage reducer, modulation of the gear faults and transmission paths to the vibration signal and the difference between the vibration energies of the gear groups increase the difficulty of diagnosing multiple simultaneous failures.

Many scholars have conducted extensive research on single reducer fault diagnosis. In particular, spur gear fault diagnosis has been studied extensively, and many related 
methods have been proposed. The proposed methods include time-frequency analysis, a wavelet method, ensemble empirical mode decomposition (EEMD), and a particle swarm optimization algorithm [4-7]. The fault types investigated include tooth surface damage, tooth breaking, wear, pitting, and cracking. In recent years, the amount of planetary gear fault diagnosis research has gradually increased. Lei et al. [8] proposed an adaptive stochastic resonance method that extracts the weak fault features of planetary gearboxes and detects sun gear faults, including chipped and missing teeth, successfully. Bartelmus and Zimroz [9] presented an indicator for monitoring planetary gearboxes under time-variable operating conditions, which is the linear dependence between the meshing frequency amplitude and operating conditions. McFadden $[10,11]$ and Samuel and Pines [12] generalized the time-domain averaging method, and respectively proposed planet and sun gear vibration separation methods. Barszcz and Randall [13] detected gear cracks in wind turbine planetary gearboxes by spectral kurtosis. Zhang et al. [14, 15] proposed a novel denoising structure and applied it to vibration signals collected from a seeded-fault testbed of the main gearbox of a helicopter. The proposed structure integrates a denoising algorithm, feature extraction, failure prognosis, and vibration modeling into a synergistic system. Chen and Feng [16] used reassigned wavelet scalograms to extract fault features from wind turbine planetary gearbox vibration signals. Feng et al. [17-20] summarized the amplitude modulation (AM) and frequency modulation (FM) characteristics in planetary gearbox vibration signals and diagnosed planetary gear faults through a variety of demodulation methods.

There are also a few studies on multiple gearbox faults. Lin and Chen [21] applied the EEMD-based method to diagnose multiple gearbox faults and successfully extracted multiple faults information from the collected signal. Teng et al. [22] proposed a complex wavelet transform-based method that can provide multiscale enveloping spectrograms (MuSEnSs) to decompose and demodulate signals simultaneously. Using this method, the weak bearing fault features buried in intensive energies can be detected readily by analyzing MuSEnSs at different scales. Zhang and $\mathrm{Yu}$ [23] proposed a novel resonance-based signal sparse decomposition (RSSD) with comb filter (CF) method in which the collected signal is firstly separated into high and low resonance components by using the RSSD method with optimal decomposition parameters. Then, both the high and low resonance components are demodulated by performing Hilbert transforms, and the fault information can be found in the Hilbert envelope spectra. Finally, a CF is constructed to extract the weaker fault feature signal from the resonance components and exclude the interference components. The studies cited above primarily focused on bearing and gear faults; there are only a few studies on simultaneous planetary and spur gear failure in reducers.

Usually, when a reducer gear fails, sensors are fixed near the planetary or spur gear, so that the vibration signal can be acquired more effectively [24]. When faults occur in a multistage reducer, the sensor should be fixed in the middle of the reducer box to collect the vibration signal of each gear. In particular, when there are planetary gears, the meshing positions of the sun and planet gears and that of the planet and ring gears are time varying with respect to the sensor, which results in vibration signal AM and makes the vibration signal more complex [25].

Some scholars have performed reducer vibration signal simulation research. Chaari et al. [26] studied the AM and FM characteristics of the vibration signal of a fixed-shaft gearbox by constructing a time-varying meshing stiffness. Omar et al. [27] built a nine degree-of-freedom model of one stage of a gear system. The model considers varying meshing stiffness, gear size, errors, and faults. Wang and McFadden [5] built a nonlinear vibration model of spur gears considering nonlinear factors such as stiffness excitation, tooth wear, and gap variation. In all these methods, vibration signals are obtained by constructing differential equations. However, it is difficult to solve the equations, and the effects of the transmission path are not considered.

Regarding planetary gears, McFadden and Smith [28], McNames [29], and Mosher [30] studied the spectral structure of planetary gearbox vibration signals and found that the vibration signal spectrum is typically asymmetric, but they did not consider factors such as the FM effect in the signal modeling. Inalpolat and Kahraman [31] proposed a mathematical model to describe the vibration signal sidebands of planetary gearboxes. Inalpolat and Kahraman [32] found that vibration signals have very complicated sidebands by studying the spectral characteristics of planetary gearbox vibration signals considering the AM caused by the planet carrier rotation and AMFM resulting from manufacturing errors. Mark and Hines [33] studied the effects of nonuniform planet loading due to gear imperfections in the sidebands of the vibration response, as well as the effects of planet carrier torque modulation. Feng and Zuo [25] developed gear damage-induced vibration signal models for planetary gearbox fault diagnosis, considering the AMFM nature of locally and diffusely damaged gear vibrations and the AM effect of time-varying vibration transfer paths, derived their Fourier spectra in closed form, and provided explicit equations for calculating the characteristic frequency of each gear in a planetary gearbox. However, the influences of the spur gear and transmission path on the vibration signal when the sensor positions are different were not considered.

Recently, some scholars have studied multistage reducer vibration signal modeling. Raclot and Velex [34] introduced a mathematical model for simulating the contributions of shape deviations and mounting errors to the dynamic behaviors of single- and multimesh geared systems. Walha et al. [35] analyzed the nonlinear dynamic system response by developing a 12 degree-of-freedom gear dynamic model that takes into account the meshing stiffness and gap changes with time. Yassine et al. [36] calculated the dynamic response of vibrations by using the Newmark method, which involves step-by-step time integration, and considers the periodic fluctuations of the mesh stiffness, eccentricity defects, profile errors, and cracked teeth. These vibration signals are obtained by solving kinetic equations, but the calculations are complex. Furthermore, the effect of the 
transmission path on the reducer vibration signal was not considered. Only a single fault was analyzed, which is different from the actual situation.

In this study, we generated the vibration signal of a multistage reducer with AM and FM caused by a timevarying transmission path, rotation frequency, and fault frequency. An explicit equation was developed to simulate the vibration signal of a multispeed reducer, and the structure of the vibration signal spectrum was obtained from the corresponding Fourier transform. In a multistage reducer, the meshing frequencies of each gear group change significantly because of rotation speed variations. Thus, the $\mathrm{AM}$ and FM of the gears at each level occur in different frequency bands. Based on this vibration signal property, this paper proposes a method of frequency and amplitude demodulation with combined variational mode decomposition (VMD) and envelope demodulation. The proposed method is significantly different from the demodulation methods used in the previous studies. When multiple failures occur, if empirical mode decomposition (EMD), EEMD, or local mean decomposition (LMD) is used to demodulate the reducer vibration signal, it cannot be ensured that the obtained separation signal contains the desired fault features. Furthermore, the number of signal demodulation layers cannot be determined if EMD, EEMD, or LMD is used, which makes it difficult to select a useful decomposition signal. In contrast, the reducer vibration signal can be decomposed according to the required frequency band because of the advantages of VMD. In this way, decomposition signals containing fault features can easily be acquired. Then, the fault features can be clearly obtained by analyzing the decomposition signal envelope. Notably, when the multistage reducer contains planetary and spur gears, their meshing frequencies often differ, which makes the method proposed in this paper widely applicable.

The remainder of this paper is organized as follows: The second section explains the principles of the VMD algorithm and the related algorithmic program. The third section describes the multistage reducer vibration signal model. The fourth section describes the application of the proposed method to a simulation signal. The fifth section discusses the verification conducted of the proposed method by presenting the analysis of experimental signals obtained when local damage (broken teeth) or distributed damage (uniform wear) occurred in the planetary and spur gears simultaneously. The sixth section presents concluding remarks.

\section{Principles and Methods}

2.1. VMD Principle. VMD is a multicomponent signal adaptive decomposition method proposed by Dragomiretskiy and Zosso [37]. To date, it has been used in areas such as bearing fault diagnosis, rotor rubbing, and speech signal detection. VMD can be employed to decompose a realvalued signal $x(t)$ into a discrete number of subsignals $u_{k}$ based on the specific sparsity properties of its bandwidth in the spectral domain. The bandwidth of a mode can be assessed via a constrained variational optimization problem with the following scheme:
(1) The real signal is transformed into an analytical signal by performing a Hilbert transform to form a one-sided frequency spectrum of the signal.

(2) The frequency spectrum of each mode is shifted to the baseband by mixing with an exponential function tuned to the relevant estimated center frequency.

(3) The bandwidth of a mode is estimated based on the Gaussian smoothness of the demodulated signal, i.e., the squared norm of the gradient.

The constrained variational problem can be written as

$$
\begin{array}{ll}
\min _{\left\{u_{k}\right\},\left\{w_{k}\right\}} & \left\{\sum_{k}\left\|\partial_{t}\left[\left(\delta(t)+\frac{j}{\pi t}\right) * u_{k}(t)\right] e^{-j w_{k} t}\right\|_{2}^{2}\right\} \\
\text { s.t. } \quad & \sum_{k} u_{k}(t)=f(t) .
\end{array}
$$

In Equation (1), $u_{k}$ is the $k$ th mode of the signal, $\left\{u_{k}\right\}$ is the set of modes $\left\{u_{1}, u_{2}, \cdots, u_{k}\right\}, w_{k}$ is the center frequency of the $k$ th mode, $\left\{w_{k}\right\}$ is the set of center frequencies of the modes $\left\{w_{1}, w_{2}, \cdots, w_{k}\right\}, f(t)$ is the signal to be decomposed, and $\delta(t)$ is the Dirac function.

Equation (1) can be expressed as an unconstrained optimization problem by introducing a quadratic penalty and Lagrangian multipliers. The modified equation with the augmented Lagrangian can be written as

$$
\begin{aligned}
L\left(\left\{u_{k}\right\},\left\{w_{k}\right\}, \lambda\right)= & \alpha \sum_{k}\left\|\partial_{t}\left[\left(\delta(t)+\frac{j}{\pi t}\right) * u_{k}(t)\right] e^{-j w_{k} t}\right\|_{2}^{2} \\
& +\left\|f(t)-\sum_{k} u_{t}(t)\right\|_{2}^{2} \\
& +\left\langle\lambda(t), f(t)-\sum_{k} u_{k}(t)\right\rangle,
\end{aligned}
$$

where $\alpha$ represents the balancing parameter of the datafidelity constraint.

Equation (2) is solved using the alternate direction method of multipliers. All the estimated modes in the frequency domain are expressed as

$$
\widehat{u}_{k}^{n+1}(w)=\frac{\widehat{f}(w)-\sum_{i \neq k} \widehat{u}_{i}(w)+(\widehat{\lambda}(w) / 2)}{1+2 \alpha\left(w-w_{k}\right)^{2}},
$$

where $\hat{f}(w), \widehat{u}_{i}(w), \hat{\lambda}(w)$, and $\widehat{u}_{k}^{n+1}(w)$ are the Fourier transforms of $f(t), u_{i}(t), \lambda(t)$, and $u_{k}^{n+1}(t)$, respectively. Note that Equation (3) is a Wiener filtering structure. The mode in the time domain can be obtained from the real part of the inverse Fourier transform of this filtered analytic signal.

The complete VMD algorithm can be summarized as follows:

(1) Initialization: let $\left\{\widehat{u}_{k}^{0}(t)\right\},\left\{\widehat{\omega}_{k}^{0}\right\},\left\{\widehat{\lambda}^{0}(t)\right\}$, and $n$ be zero and predefine a convergence threshold $\varepsilon$ and the number of intrinsic mode functions (IMFs) $K$ to be separated. 
(2) Update each IMF $u_{k}(t)$ and its associated center frequency $\omega_{k}$, for $k=1: k$ and $\omega \geq 0$ :

$$
\begin{aligned}
& u_{k}^{n+1}(\omega)=\frac{\widehat{x}(\omega)-\sum_{i<k} \widehat{u}_{i}^{n+1}(\omega)-\sum_{i>k} \widehat{u}_{i}^{n}(\omega)+(1 / 2) \widehat{\lambda}^{n}(\omega)}{1+2 \alpha\left(\omega-\omega_{k}^{n}\right)^{2}}, \\
& \widehat{\omega}_{k}^{n+1}(\omega)=\frac{\int_{0}^{\infty} \omega\left|\widehat{u}_{k}^{n+1}(\omega)\right|^{2} d \omega}{\int_{0}^{\infty}\left|\widehat{u}_{k}^{n+1}(\omega)\right|^{2} d \omega} .
\end{aligned}
$$

(3) Update the Lagrangian multiplier for all $\omega \geq 0$ :

$$
\widehat{\lambda}^{n+1}(\omega)=\widehat{\lambda}^{n}(\omega)+\tau\left[\widehat{x}(\omega)-\sum_{k} \widehat{u}_{k}^{n+1}(\omega)\right] \text {, }
$$

where $\tau$ is the Lagrangian multiplier update parameter.

(4) Check the convergence condition:

$$
\sum_{k} \frac{\left\|\widehat{u}_{k}^{n+1}(t)-\widehat{u}_{k}^{n}(t)\right\|_{2}^{2}}{\left\|\widehat{u}_{k}^{n+1}(t)\right\|_{2}^{2}}<\varepsilon .
$$

If it is met, let $u_{k}(t)=\widehat{u}_{k}^{n+1}(t)$ and $\omega_{k}=\omega_{k}^{n+1}$ and terminate the decomposition. Otherwise, let $n=n+1$ and return to Step 2.

2.2. Procedure. The basic steps of the signal processing algorithm proposed in this paper are as follows: Firstly, to avoid the influence of high-frequency harmonics, a low-pass filter is used to filter the vibration signal. Then, VMD is performed to decompose the filtered vibration signal to obtain three VIMFs (the IMFs acquired by VMD) ranging from low frequency to high frequency. Finally, the envelope spectrum is employed to analyze VIMF1 and VIMF3, which, respectively, include the spur gear and planetary gear vibration information. Multiple multistage reducer faults can be diagnosed by observing the characteristic frequency changes of the gear fault envelope spectrum.

\section{Vibration Signal Model}

The sensor is usually fixed onto the multistage reducer box when measuring vibrations. Vibration signals are transmitted to the sensor through multiple paths when the gears mesh. The vibration signals of each gear group are addressed in this section.

3.1. Gear Vibration Signal Model. The vibration signals of each gear group (with no distinction between planetary and spur gears) in a fault reducer can be modeled by the AM and FM process. The meshing frequency of the gears or their multiple frequencies is the carrier frequency of the signal, and the characteristic frequency of the damaged gear or its multiple frequencies is the modulation frequency.

The model of normal gear meshing vibration is as follows:

$$
\begin{aligned}
x(t) & =h(t) \sum_{k=0}^{K} V_{k}(t), \\
V_{k}(t) & =\cos \left(2 \pi k f_{\mathrm{m}} t+\theta_{k}\right),
\end{aligned}
$$

where $h(t)$ is the influence of the transmission path on the vibration signal, $V_{k}(t)$ is the meshing vibration of the normal gear, $K$ is the highest order, $f_{\mathrm{m}}$ is the meshing frequency, and $\theta_{k}$ is the initial phase.

When the gear is damaged,

$$
\begin{aligned}
x^{\mathrm{F}}(t) & =h(t) \sum_{k=1}^{K} a_{k}(t) V_{k}^{\mathrm{F}}(t), \\
V_{k}^{\mathrm{F}}(t) & =\cos \left[\left(2 \pi k f_{\mathrm{m}} t\right)+b_{k}(t)+\theta_{k}\right],
\end{aligned}
$$

where $a_{k}(t)$ is the AM function caused by the fault, $V_{K}^{\mathrm{F}}(t)$ is the meshing vibration of the faulty gear, and $b_{k}(t)$ is the FM function caused by the fault:

$$
\begin{aligned}
a_{k}(t) & =c \sum_{m=1}^{M} A_{k n} \cos \left(2 \pi m f_{\mathrm{F}} t+\phi_{k n}\right) \\
& =c\left[1+\sum_{n=0}^{N} A_{k n} \cos \left(2 \pi m t+\phi_{k n}\right)\right], \\
b_{k}(t) & =\sum_{l=1}^{L} B_{k l} \sin \left(2 \pi l f_{\mathrm{F}} t+\varphi_{k l}\right)
\end{aligned}
$$

where $c$ is a dimensionless constant dependent on the signal amplitude; $A_{k n}$ and $B_{k l}$ are the AM and FM coefficients, respectively $\left(A_{k n}>0, B_{k l}>0\right) ; \phi_{k n}$ and $\varphi_{k l}$ are the initial phases; $f_{\mathrm{F}}$ is the characteristic frequency of the fault; and $M$ and $L$ are the highest orders of modulation.

3.2. Influence of the Transmission Path. In a multistage reducer, the vibration signal generated by each gear group is transmitted to the sensor along multiple paths. We analyzed the influence of the transmission path on the vibration signal by using an example of a three-stage gear transmission system (including a planetary gear and two spur gears, as shown in Figure 1). We discuss the planetary and spur gears separately as their transmission paths are different. For simplicity, we only consider the case of order $1(K=1, L=1, M=1)$.

3.2.1. Planetary Gear Vibration Signal. A planetary gear is typically composed of a sun gear, several planet gears, and a ring gear. Usually, the ring gear is stationary, and the sun and planet gears as well as the planet and ring gears mesh simultaneously. Owing to the revolution of the planet gears, the transmission path between the meshing point and sensor varies periodically. Figure 1 shows six transmission paths according to planetary gear. Taking a planet gear as the object of analysis, the transmission of a vibration signal from the meshing point of the planetary and sun gears to the sensor occurs along paths 1-3 in Figure 1, and that from the meshing point of the planetary and ring gears to the sensor occurs along paths 4-6. In addition to these six transmission paths, the vibrations will be transmitted to the sensor 


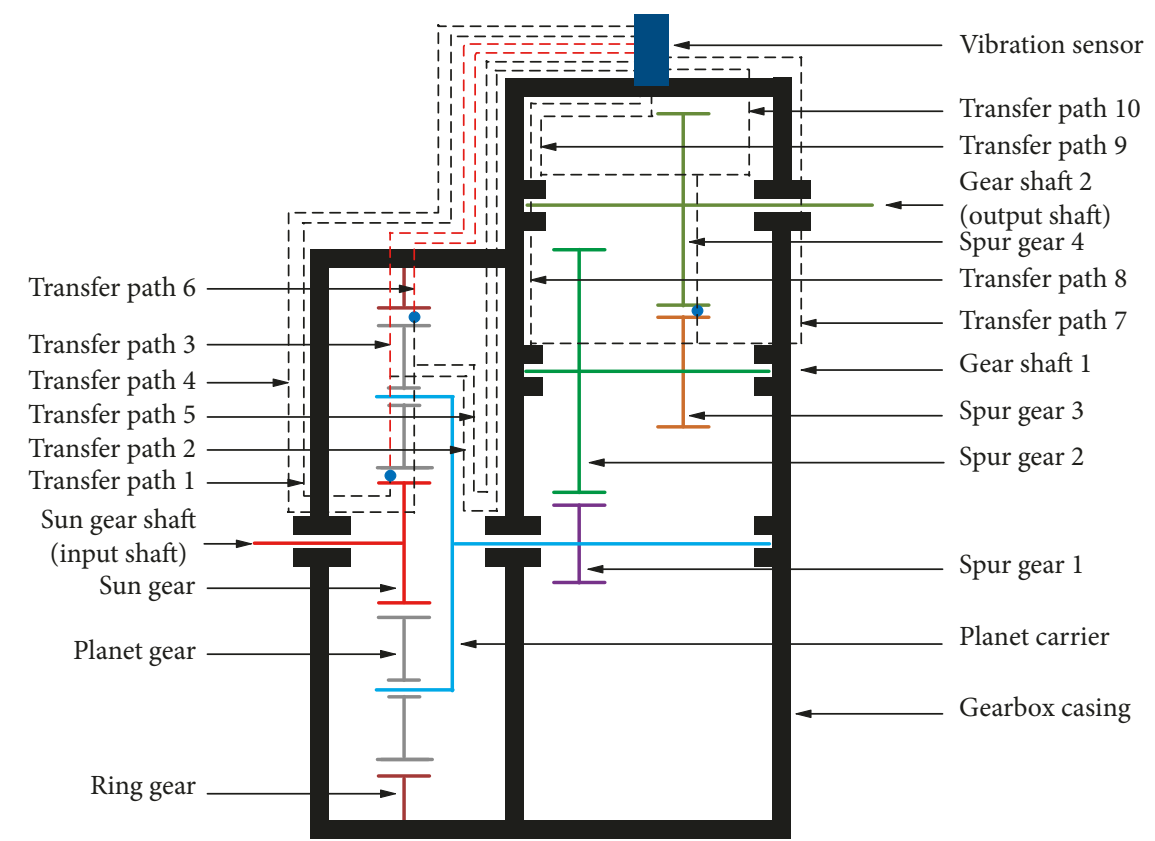

Figure 1: Transmission paths of the vibration signals in a multistage reducer.

through the oil, box, etc. However, these vibrations are weak and therefore are not addressed in this article.

The transmission paths of the planetary gear are as follows:

Path 1: sun gear $\longrightarrow$ sun gear shaft $\longrightarrow$ reducer box $\longrightarrow$ sensor

Path 2: sun gear $\longrightarrow$ planet gear $\longrightarrow$ ring gear $\longrightarrow$ reducer box $\longrightarrow$ sensor

Path 3: sun gear $\longrightarrow$ planetary gear $\longrightarrow$ planet gear shaft $\longrightarrow$ planet carrier $\longrightarrow$ reducer box $\longrightarrow$ sensor

Path 4: planet gear $\longrightarrow$ sun gear $\longrightarrow$ sun gear shift $\longrightarrow$ reducer box $\longrightarrow$ sensor

Path 5: planet gear $\longrightarrow$ planet gear shift $\longrightarrow$ planet carrier $\longrightarrow$ reducer box $\longrightarrow$ sensor

Path 6: planet gear $\longrightarrow$ ring gear $\longrightarrow$ reducer box $\longrightarrow$ sensor

For transmission paths 2 and 6 , the position of the meshing point of each gear pair changes constantly. The time variation of the meshing point location makes the distance between the vibration source and sensor change periodically. The vibration signal amplitude measured by the sensor is large when the planet gear is rotated just below the sensor. Conversely, this amplitude is small when the planet wheel is rotated away from the sensor. Therefore, transmission paths 2 and 6 modulate the vibration signal amplitude. The modulation frequency is the planet gear revolution frequency, that is, the planet carrier rotation frequency. The remaining four transmission paths will not change owing to the planet gear revolution. They will change the vibration signal amplitude but will not introduce a new modulation frequency. The signals of these four paths are considered as a whole when simulating the vibration signal. Transmission paths 2 and 6 can be represented by Hanning windows, and they are synchronous. The lengths of transmission paths 2 and 6 are different; thus, the attenuation is different. $A_{\mathrm{rl}}(t)$ is the function of transmission path 6 where the first planet gear and ring gear mesh, and $A_{\mathrm{s} 1}(t)$ is the function of transmission path 2 where the first planet gear and sun gear mesh:

$$
\begin{aligned}
& A_{\mathrm{r} 1}(t)=1-\cos \left(2 \pi f_{\mathrm{c}} t\right), \\
& A_{\mathrm{s} 1}(t)=k_{1} A_{\mathrm{r} 1}(t),
\end{aligned}
$$

where $k_{1}$ is an attenuation coefficient and $k_{1}<1$, and $f_{\mathrm{c}}$ is the planet carrier rotation frequency.

For transmission path 6 , the transmission paths of the other planet gears are

$$
A_{\mathrm{r} i}(t)=A_{\mathrm{r} 1}\left(\frac{t+(i-1) T}{3}\right),
$$

where $T$ is the planet gear revolution period.

For transfer path 2, the transmission paths of the other planet gears are

$$
A_{\mathrm{s} i}(t)=A_{\mathrm{s} l}\left(\frac{t+(i-1) T}{3}\right) .
$$

The transfer functions of the remaining four paths can be considered to be constants, where paths 1 and 3 are expressed in $A_{1}$, and paths 4 and 5 are expressed in $A_{2}$.

Therefore, considering the influence of all the paths, the vibration signal of the planetary gear can be represented as follows:

$$
\begin{aligned}
x_{p}(t)= & \sum_{i=1}^{N} A_{\mathrm{r} i}(t) V_{\mathrm{rp} i}(t)+A_{\mathrm{s} i} V_{\mathrm{sp} i}(t)+A_{1} V_{\mathrm{rp} i}(t) \\
& +A_{2} V_{\mathrm{sp} i}(t)
\end{aligned}
$$

where $V_{\mathrm{rpi}}(t)$ and $V_{\mathrm{spi}}(t)$ are the meshing vibrations of planet gear $i$ with the ring gear and sun gear, respectively, and $\mathrm{N}$ is the number of planet gears: 


$$
V_{\mathrm{rp} i}(t)=V_{\mathrm{sp} i}(t)=\cos \left(2 \pi f_{\mathrm{m}} t+\frac{i-1}{N} T+\theta\right) .
$$

When the sun gear has a fault,

$$
\begin{aligned}
x_{\mathrm{p}}^{\mathrm{S}}(t)= & \sum_{i=1}^{N} A_{\mathrm{r} i}(t) V_{\mathrm{rp} i}(t)+A_{\mathrm{si} i} a_{i}(t) V_{\mathrm{sp} i}^{\mathrm{F}}(t)+A_{1} V_{\mathrm{rp} i}(t) \\
& +A_{2} a_{i}(t) V_{\mathrm{sp} i}^{\mathrm{F}}(t), \\
V_{\mathrm{sp} i}^{\mathrm{F}}(t)= & \cos \left(2 \pi f_{\mathrm{m}} t+b_{i}(t)+\frac{i-1}{N} T+\theta\right) .
\end{aligned}
$$

Further, when the planet gear has a fault (assuming the failure of planet gear $j$ ),

$$
\begin{aligned}
x_{\mathrm{p}}^{\mathrm{P}}(t)= & \sum_{i-1}^{N-1}\left[A_{\mathrm{r} i}(t) V_{\mathrm{rp} i}(t)+A_{\mathrm{s} i}(t) V_{\mathrm{sp} i}(t)+A_{1} V_{\mathrm{rp} i}(t)\right. \\
& \left.+A_{2} V_{\mathrm{sp} i}(t)\right]+\left[A_{\mathrm{r} j}(t) a_{j}(t) V_{\mathrm{rp} j}^{\mathrm{F}}(t)\right. \\
& +A_{\mathrm{s} j}(t) a_{j}(t) V_{\mathrm{sp} j}^{\mathrm{F}}(t)+A_{1} a_{j}(t) V_{\mathrm{rp} j}^{\mathrm{F}}(t) \\
& \left.+A_{2} a_{j}(t) V_{\mathrm{sp} j}^{\mathrm{F}}(t)\right] .
\end{aligned}
$$

The form of $V_{\mathrm{rp} j}^{\mathrm{F}}(t)$ is similar to that of $V_{\mathrm{sp} j}^{\mathrm{F}}(t)$.

3.2.2. Spur Gear Vibration Signal. The spur gear transmission path is simple. When the normal gear is meshing, the vibration signal is mainly derived from the meshing position of the gear. The transmission path of the signal to the sensor is mainly along the two gear shafts (paths 7-10 in Figure 1). As these paths are not time varying, they only affect the vibration signal amplitude. These four transfer path functions are regarded as a constant $A_{3}$ :

$$
\begin{aligned}
h_{\mathrm{s}}(t) & =A_{3}, \\
V_{\mathrm{s}} & =\cos \left(2 \pi f_{\mathrm{m}} t+\varphi\right) .
\end{aligned}
$$

The vibration signals of a spur gear fault can be expressed as

$$
\begin{aligned}
x_{\mathrm{s}}^{\mathrm{F}}(t) & =A_{3} a(t) V_{\mathrm{s}}^{\mathrm{F}}(t), \\
V_{\mathrm{s}}^{\mathrm{F}}(t) & =\cos \left(2 \pi f_{\mathrm{m}} t+b(t)+\varphi\right) .
\end{aligned}
$$

\subsection{Characteristic Frequency of Faulty Gear}

\subsubsection{Characteristic Frequency of Faulty Planetary Gear.}

\section{(1) Characteristic Frequency of Local Gear Damage.}

\section{Sun Gear}

In each relative rotating cycle, a damaged sun gear tooth comes into contact with all of the planet gears. Thus, the characteristic frequency of a locally damaged sun gear is equal to the number of planet gears times the relative rotation frequency of the sun gear with respect to the planet carrier:

$$
\begin{aligned}
& f_{\mathrm{s}}^{\mathrm{l}}=\frac{f_{\mathrm{m}}}{Z_{\mathrm{s}}} N=N f_{\mathrm{s}}, \\
& f_{\mathrm{s}}=\frac{f_{\mathrm{m}}}{Z_{\mathrm{s}}} .
\end{aligned}
$$

\section{Planet Gear}

A locally damaged planet gear has two characteristic frequencies because it contacts the ring and sun gears simultaneously. One of those frequencies is

$$
\begin{gathered}
f_{\mathrm{p} 1}^{\mathrm{l}}=\frac{f_{\mathrm{m}}}{Z_{\mathrm{p}}}=f_{\mathrm{p}}, \\
f_{\mathrm{p}}=\frac{f_{\mathrm{m}}}{Z_{\mathrm{p}}}
\end{gathered}
$$

If the damage exists on one side of the planet gear tooth, the damaged area contacts mating gears (either the sun or ring gear) only once in each relative rotating cycle. Meanwhile, if the damage occurs on both sides of the planet gear tooth, the damaged area contacts mating gears (both the sun and ring gears) twice in each relative rotating cycle, and the frequency is twice that of Equation (20):

$$
f_{\mathrm{p} 2}^{\mathrm{l}}=2 \frac{f_{\mathrm{m}}}{Z_{\mathrm{p}}}=2 f_{\mathrm{p}} .
$$

\section{Ring Gear}

Similarly, the characteristic frequency of a locally damaged ring gear is

$$
\begin{aligned}
& f_{\mathrm{r}}^{\mathrm{l}}=\frac{f_{\mathrm{m}}}{Z_{\mathrm{r}}} N=N f_{\mathrm{r}}, \\
& f_{\mathrm{r}}=\frac{f_{\mathrm{m}}}{Z_{\mathrm{r}}} .
\end{aligned}
$$

(2) Characteristic Frequency of Distributed Gear Damage. In the case of distributed gear damage, the characteristic frequency of a faulty gear is defined as its rotation frequency relative to the planet carrier (in the cases of sun and ring gear damage) or to the ring gear (in the case of planet gear damage), because distributed gear damage modulates the gear meshing vibrations with a period equal to the damaged gear rotating cycle relative to the planet carrier or ring gear. In this sense, the characteristic frequencies of planet, sun, and ring gears with distributed damage can be calculated using

$$
\begin{aligned}
& f_{\mathrm{s}}^{\mathrm{d}}=\frac{f_{\mathrm{m}}}{Z_{\mathrm{s}}}=f_{\mathrm{s}}, \\
& f_{\mathrm{p}}^{\mathrm{d}}=\frac{f_{\mathrm{m}}}{Z_{\mathrm{p}}}=f_{\mathrm{p}}, \\
& f_{\mathrm{r}}^{\mathrm{d}}=\frac{f_{\mathrm{m}}}{Z_{\mathrm{r}}}=f_{\mathrm{r}} .
\end{aligned}
$$


3.3.2. Characteristic Frequency of Faulty Spur Gear. The characteristic frequencies of a faulty spur gear with local and distributed damage are

$$
\begin{aligned}
& f^{\mathrm{l}}=f_{\mathrm{r}}, \\
& f^{\mathrm{d}}=f_{\mathrm{m}},
\end{aligned}
$$

respectively.

\section{Simulated Signal Analysis}

To illustrate the effectiveness of the proposed method, we simulated the vibration signal of a three-stage reducer (including one planetary gear and two spur gears). The firststage planetary gear and third-stage spur gear were equipped with gear faults separately. Without loss of generality, we ignored the influence of the initial phase and focused on analyzing the meshing and characteristic frequencies of the faults. To simulate the background noise interference, we added Gaussian noise $N(t)$, and the signal-to-noise ratio was $20 \mathrm{~dB}$. The simulation signal model was as follows:

$$
x(t)=x_{\mathrm{p}}^{\mathrm{F}}(t)+x_{\mathrm{s}}(t)+x_{\mathrm{s}}^{\mathrm{F}}(t)+N(t)
$$

where

$$
\begin{aligned}
x_{\mathrm{p}}^{\mathrm{F}}(t)= & \sum_{i=1}^{N} A_{\mathrm{r} i}(t) V_{\mathrm{rp} i}(t)+A_{\mathrm{s} i} a_{i}(t) V_{\mathrm{sp} i}^{L}(t)+A_{1} V_{\mathrm{rp} i}(t) \\
& +A_{2} a_{i}(t) V_{\mathrm{sp} i}^{L}(t), \\
A_{\mathrm{r} i}(t)= & k_{\mathrm{r} i}\left(1-\cos \left(2 \pi f_{\mathrm{c}} t+\frac{(i-1)}{N} T\right)\right), \\
V_{\mathrm{rp} i}(t)= & \cos \left(2 \pi f_{\mathrm{m}} t+\frac{i-1}{N} T\right), \\
A_{\mathrm{s} i}(t)= & k_{\mathrm{s} i}\left(1-\cos \left(2 \pi f_{\mathrm{c}} t-\frac{(i-1)}{N} T\right)\right), \\
a_{i}(t)= & 1+A_{\mathrm{p}} \cos \left(2 \pi f_{\mathrm{s}} t+\frac{(i-1)}{N} T\right), \\
V_{\mathrm{sp} i}^{\mathrm{F}}(t)= & \cos \left(2 \pi f_{\mathrm{m} 1} t+B_{\mathrm{p}} \sin \left(2 \pi f_{\mathrm{s}} t\right)+\frac{(i-1)}{N} T\right), \\
x_{\mathrm{s}}^{\mathrm{F}}(t)= & \sum_{l=1}^{5} A_{4}\left(1+A_{\mathrm{s}} \cos \left(2 \pi f_{\mathrm{r} 1} t\right)\right) \\
x_{\mathrm{s}}(t)= & \sum_{i=1}^{5} A_{3} \cos \left(2 \pi l f_{\mathrm{m} 2} t\right), \\
& \cos \left(2 \pi l f_{\mathrm{m}}+B_{\mathrm{s}} \sin \left(2 \pi f_{\mathrm{r} 1} t\right)\right) . \\
& \\
&
\end{aligned}
$$

The relevant parameters in these formulas are listed in Table 1. The parameters of the related frequencies were obtained based on the experimental data (the simulation
TABLE 1: Simulation signal parameters.

\begin{tabular}{lcc}
\hline Meshing frequency of planetary gear & $f_{\mathrm{m} 1}(\mathrm{~Hz})$ & 648 \\
Meshing frequency of spur gear 1 & $f_{\mathrm{m} 2}(\mathrm{~Hz})$ & 188 \\
Meshing frequency of spur gear 2 & $f_{\mathrm{m} 3}(\mathrm{~Hz})$ & 68 \\
Rotation frequency of planet carrier & $f_{\mathrm{c}}(\mathrm{Hz})$ & 6.5 \\
Characteristic frequency of spur gear fault & $f_{\mathrm{r} 1}(\mathrm{~Hz})$ & 1.9 \\
Characteristic frequency of the sun gear fault & $f_{\mathrm{s}}(\mathrm{Hz})$ & 23 \\
AM coefficient of path ii & $k_{\mathrm{ri}}$ & 0.03 \\
AM coefficient of path vi & $k_{\mathrm{si}}$ & 0.03 \\
AM coefficient of the sun gear fault & $A_{\mathrm{p}}$ & 1 \\
FM coefficient of the sun gear fault & $B_{\mathrm{p}}$ & 2 \\
AM coefficient of paths 1 and 3 & $A_{1}$ & 0.03 \\
AM coefficient of paths 4 and 5 & $A_{2}$ & 0.03 \\
AM coefficient of the paths to the vibration & $A_{3}$ & 0.09 \\
signal of spur gear 1 & & \\
AM coefficient of the paths to the vibration & $A_{4}$ & 0.06 \\
signal of spur gear 2 & $A_{\mathrm{s}}$ & 1 \\
AM coefficient of the spur gear fault & $B_{\mathrm{s}}$ & 1.5 \\
FM coefficient of the spur gear fault & &
\end{tabular}

signal corresponds to the actual fault type Sun Gear WearSpur Gear Broken Teeth). The coefficients were obtained based on the amplitude of the actual vibration signal and rounded off. We tried to make the amplitude of the simulation signal similar to that of the actual vibration signal by adjusting the coefficients. This ensures that the ratio of the vibrational energy of the spur gear to the planetary gear is similar to that of the actual vibration signal. It further ensures that the fault feature signal of the spur gear is submerged in the simulation signal like the reality. The sampling frequency was set to $2000 \mathrm{~Hz}$.

We analyzed the simulation signals in accordance with the program described in Section 2.2. The results are shown in Figure 2.

Figure 2(b) shows the Fourier spectrum of the simulation signal. In the frequency domain, virtually all of the prominent spectral peaks appear at the expected characteristic frequencies-such as the meshing frequencies of spur gears $1\left(f_{\mathrm{m} 2}\right)$ and $2\left(f_{\mathrm{m} 3}\right)$, their product frequencies $\left(n f_{\mathrm{m} 2}\right.$, $\left.n f_{\mathrm{m} 3}\right)$, and the planetary gear meshing frequency $\left(f_{\mathrm{m} 1}\right)$. There is a sideband $\left(n f_{\mathrm{m} 3} \pm k f_{\mathrm{r} 1}\right)$ associated with the spur gear failure frequency near the meshing frequency of spur gear 2. Complex sidebands appear near the planetary gear meshing frequency, including peaks such as those at $f_{\mathrm{m} 1} \pm f_{\mathrm{c}}, f_{\mathrm{m} 1} \pm f_{\mathrm{s}}, f_{\mathrm{m} 1} \pm n f_{\mathrm{c}}, f_{\mathrm{m} 1} \pm n f_{\mathrm{s}}$, and $f_{\mathrm{m} 1} \pm$ $n f_{\mathrm{s}} \pm n f_{\mathrm{e}}$. Because the spur gear vibration energy is less than that of the planetary gear, and the planetary gear spectrum is complex, it is difficult to diagnose the gear faults via traditional Fourier spectrum analysis when the spur and sun gears fail simultaneously.

Figure 2(c) depicts the simulation signal envelope spectrum and clearly reveals the carrier frequency $\left(f_{\mathrm{c}}\right)$, sun gear fault characteristic frequency $\left(f_{\mathrm{s}}\right)$, and modulation frequency between them $\left(f_{\mathrm{s}} \pm f_{\mathrm{c}}\right)$. However, the spur gear fault features do not appear in the envelope spectrum. Therefore, to extract the fault information of each gear effectively, we used the method proposed in this paper. We employed VMD to decompose the simulation signal and obtain VIMFs (Figure 2(d)). The instantaneous frequency spectrogram shows that the frequency of VIMF1 is mainly concentrated in the $0-300 \mathrm{~Hz}$ 


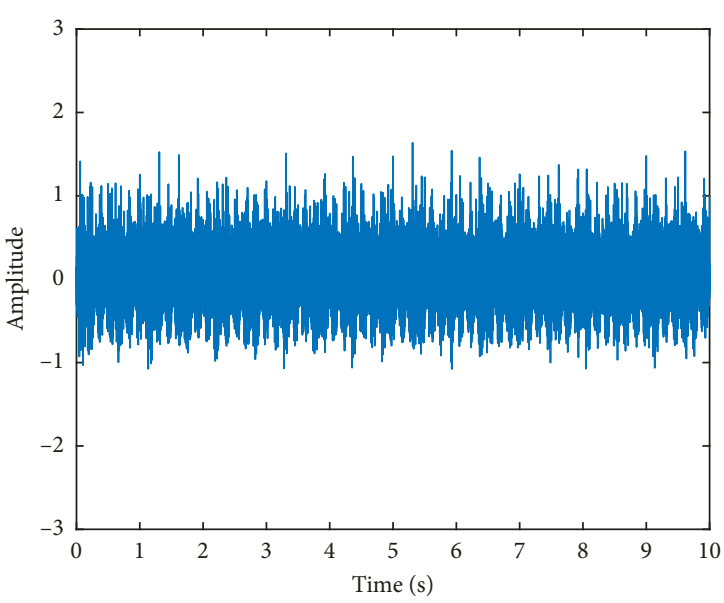

(a)

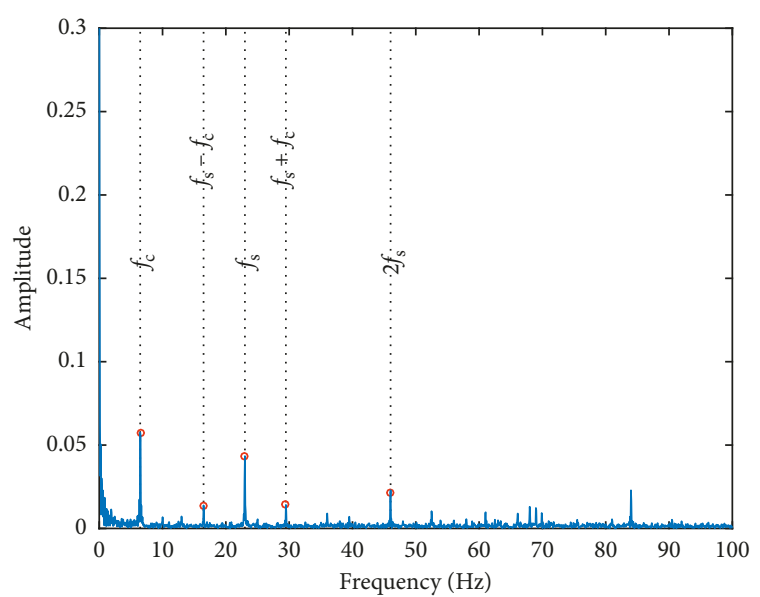

(c)

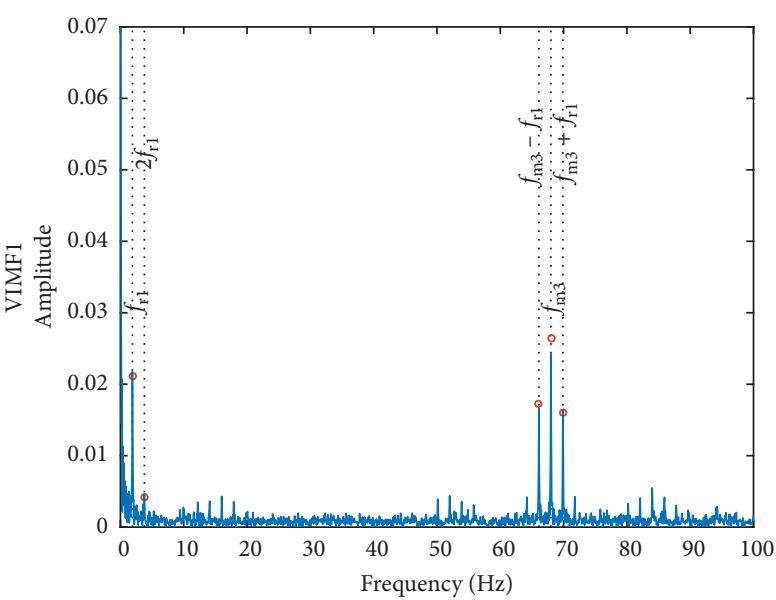

(e)

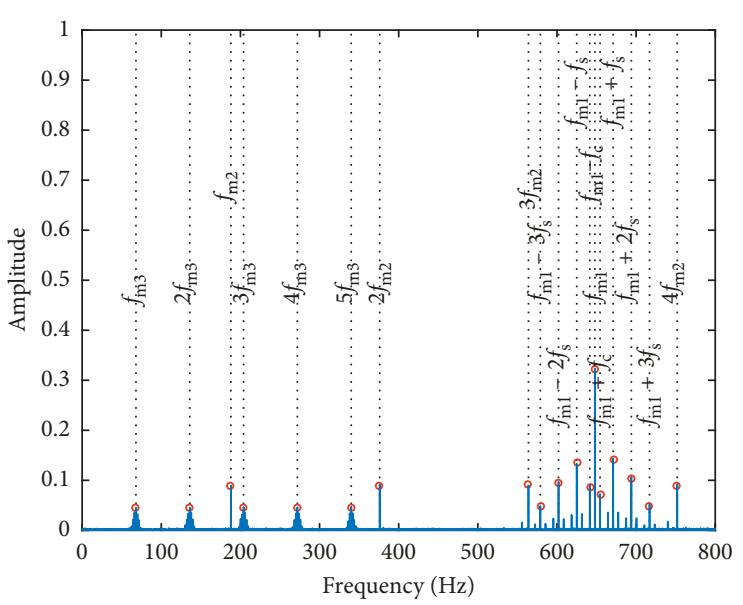

(b)
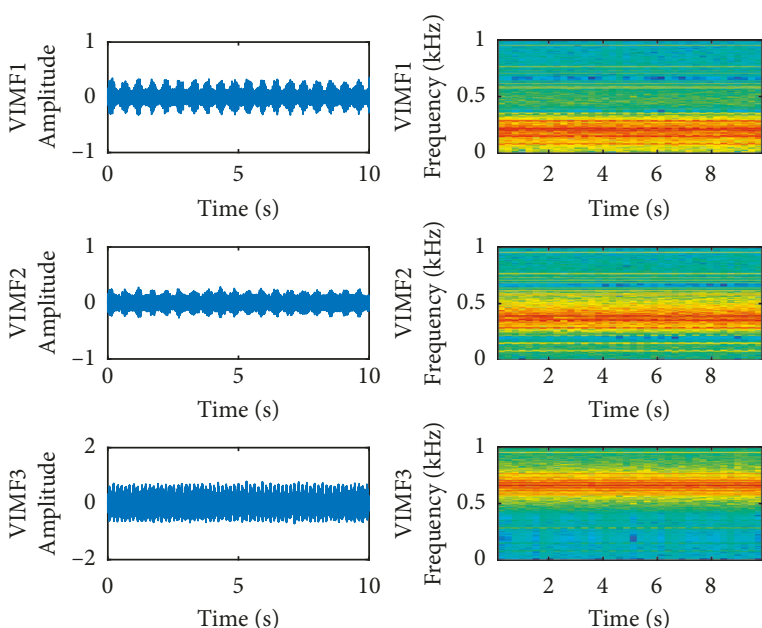

(d)

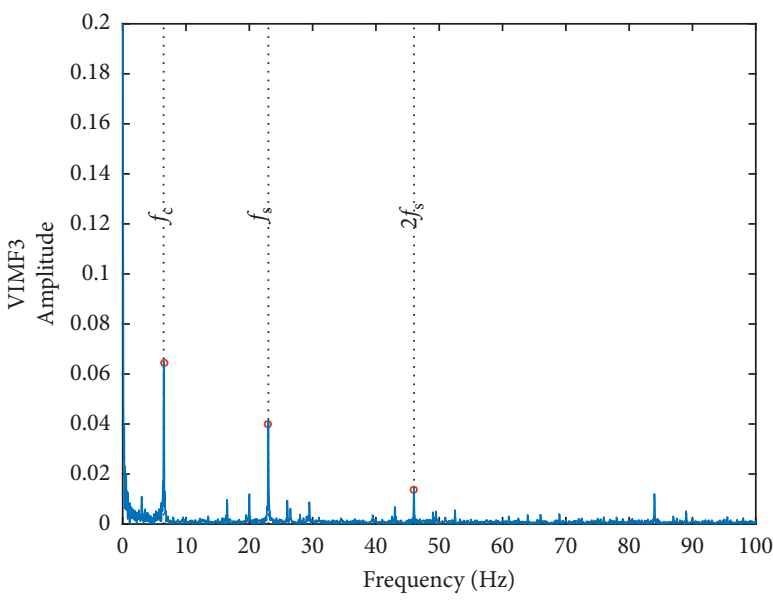

(f)

FIGURE 2: Simulation results: (a) time-domain waveform of simulation signal, (b) spectrum of simulation signal, (c) envelope spectrum of simulation signal, (d) time-domain and time-frequency VMD decomposition images, (e) envelope of VIMF1, and (f) envelope of VIMF3.

range, which mainly contains the vibration information of spur gear 2, and the frequency of VIMF3 is mainly focused in the $600-800 \mathrm{~Hz}$ range, which mainly contains the vibration information of the sun wheel. Envelope spectra were acquired separately for VIMF1 and VIMF3.
Figure 2(e) clearly shows the fault feature frequency of the spur gears $\left(f_{\mathrm{rl}}\right)$, its modulation frequency, and the meshing frequency of spur gear $2\left(f_{\mathrm{m} 3} \pm f_{\mathrm{r} 1}\right)$. Figure $2(\mathrm{f})$ clearly provides the fault feature frequencies of the sun gear $\left(f_{\mathrm{s}}\right)$ and the planet carrier $\left(f_{\mathrm{c}}\right)$. Compared with the 
traditional Fourier transform, Figures 2(e) and 2(f) more clearly show the gears corresponding to the fault characteristics. Thus, the proposed method not only enables effective diagnosis of spur gear faults, but also facilitates planetary gear fault diagnosis. The above simulation signal analysis illustrates the effectiveness of the proposed method for extracting multiple faults in a multistage reducer.

\section{Experimental Signal Analysis}

In this section, we verify the effectiveness of the proposed method by presenting experimental data. To obtain these data, we fabricated local faults (broken teeth) and distributed faults (uniform wear) on the planetary and spur gears of the reducer.

5.1. Experimental Specifications. Figure 3 shows the multistage reducer test rig. The reducer included three gear transmission stages: a first-stage planetary gear, secondstage spur gear, and third-stage spur gear. A magnetic powder brake was used to provide the entire system load. Table 2 lists the parameters of the multistage reducer test rig.

We processed the local faults (broken teeth) and distributed faults (uniform wear) on the sun gear of the firststage planetary gear and the second-stage spur gear. Figure 4 shows the different fault types of the sun and spur gears. We artificially destroyed about $20 \%$ of one sun gear tooth to represent a local fault (broken tooth) and cut about $0.3 \mathrm{~mm}$ off each sun gear tooth to represent a distributed fault (uniform wear). The same fault types were also processed on the third-stage spur gear artificially. The other gears were normal in each experiment. In the experiment, we set the rotation frequency of the motor to $1800 \mathrm{rpm} / \mathrm{min}$ and the output torque of the magnetic brake to $1 \mathrm{~N} \cdot \mathrm{m}$.

The acceleration sensor was fixed in the middle of the reducer box so that the vibration information of the reducer at each gear stage could be collected. The vibration signal sampling frequency was $10 \mathrm{kHz}$.

According to the structure and rotation speed of the planetary and spur gears, the rotation frequency of the gears at each stage and the characteristic frequency of the faulty gear were calculated; the results are presented in Table 3.

5.2. Multifault Experiment Signal Analysis. In this section, we outline the experimental signal analysis performed using the program proposed in Section 2.2. We analyzed the experimental signals of the reducer box when the planet and spur gears experienced local faults (broken teeth) or distributed faults (uniform wear) to demonstrate the effectiveness of the method. In all the following figures, the blue line indicates the baseline signal and the red line indicates the fault signal.

5.2.1. Baseline: All of the Gears Are Perfect. Figures 5(a) and 5(b) depict the time-domain waveforms of the original and

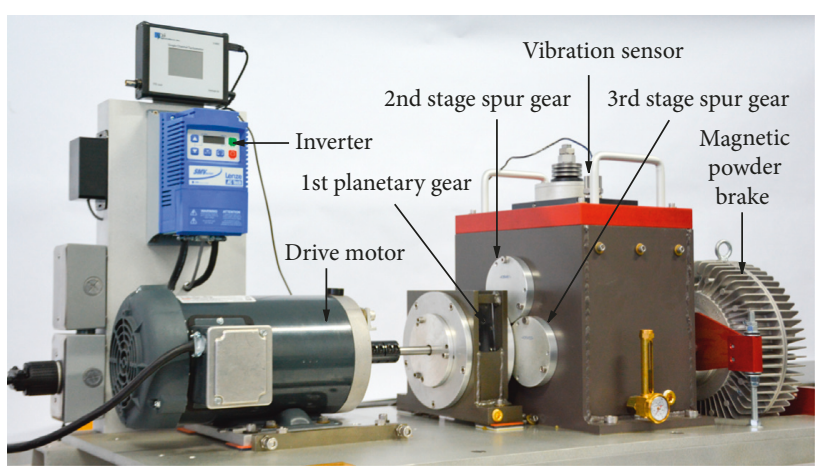

Figure 3: Multistage reducer test rig.

filtered vibration signals, respectively. From the spectrum of the filtered vibration signal (Figure 5(c)), the motor rotation frequency $\left(f_{\mathrm{s}}^{(\mathrm{r})}\right)$, planetary gear meshing frequency $\left(f_{\mathrm{m} 1}\right)$, spur gear meshing frequencies $\left(f_{\mathrm{m} 2}, f_{\mathrm{m} 3}\right)$, and multiples of the spur gear meshing frequencies $\left(n f_{\mathrm{m} 2}, n f_{\mathrm{m} 3}\right)$ can be identified. Sidebands appear near the spur gear meshing frequency, which is mainly caused by the gear shaft rotation frequency. There are also sidebands near the planetary gear meshing frequency, but the form is relatively complex, mainly because of the planet gear and planet carrier rotation frequencies and their combined frequency. Comparison of the amplitudes of the planetary and spur gear spectra shows that the spur gear vibration amplitude is smaller than that of planetary gear, especially for the third-stage spur gear. Thus, the planetary gear vibration energy is greater than that of the spur gear. Therefore, only the characteristic frequency of the planetary gear can be seen in the vibration signal envelope spectrum. In the envelope spectrum, the rotation frequencies of the planet gear and planet carrier, multiples of their frequencies, and their combined frequency can be seen. The meshing frequency of the second-stage spur gear is observable, but the rotation frequency associated with the spur gear is not visible.

After VMD decomposition, we obtained three VIMFs. Figure 5(e) presents the time-domain and time-frequency images for each VIMF, revealing that the three VIMFs are in different frequency bands. VIMF1 and VIMF3 mainly contain the vibration information of the spur and planetary gears, respectively. Then, the envelope spectra of VIMF1 and VIMF3 were obtained separately. Figure $5(\mathrm{f})$ shows the envelope spectrum of VIMF1, revealing the multiples of the rotating frequencies of the second spur gear $\left(n f_{\mathrm{rl}}\right)$ and the third spur gear $\left(n f_{\mathrm{r} 2}\right)$, the meshing frequency of the third spur gear $\left(f_{\mathrm{m} 3}\right)$, and the modulation frequencies between them $\left(f_{\mathrm{m} 3} \pm n f_{\mathrm{r} 1}, f_{\mathrm{m} 3} \pm n f_{\mathrm{r} 2}\right)$ which are related to the characteristic frequency of the spur gears. Figure $5(\mathrm{~g})$ depicts the envelope spectrum of VIMF3, revealing the rotation frequency of the planet carrier $\left(f_{c}\right)$, characteristic frequency of the planet gear $\left(f_{\mathrm{p}}\right)$, characteristic frequency of the sun gear $\left(f_{\mathrm{s}}\right)$, their multiples $\left(n f_{\mathrm{c}}, i f_{\mathrm{p}}, m f_{\mathrm{s}}\right)$, and the modulation frequencies between them $\left(m f_{\mathrm{s}} \pm i f_{\mathrm{p}} \pm n f_{\mathrm{c}}\right)$, which are related to the characteristic frequency of the planetary gear. In an actual reducer, manufacturing and assembly error is inevitable, leading to the occurrence of these frequency components in the FM spectrum. 
TABLE 2: Multistage reducer parameters.

\begin{tabular}{lcccccccc}
\hline \multirow{2}{*}{$\begin{array}{l}\text { Parameter } \\
\end{array}$} & \multicolumn{3}{c}{ First-stage planetary gear } & \multicolumn{2}{c}{ Second-stage spur gear } & \multicolumn{2}{c}{ Third-stage spur gear } \\
& Sun gear & Planet gear & Ring gear & Number of planet gears & Driving gear & Driven gear & Driving gear & Driven gear \\
\hline Number of teeth & 28 & 36 & 100 & 4 & 29 & 100 & 36 \\
\hline
\end{tabular}

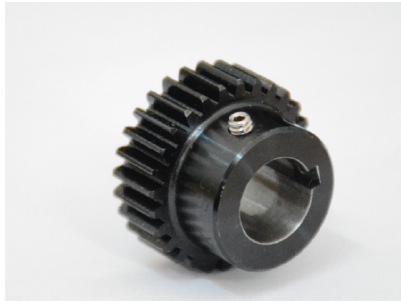

(a)

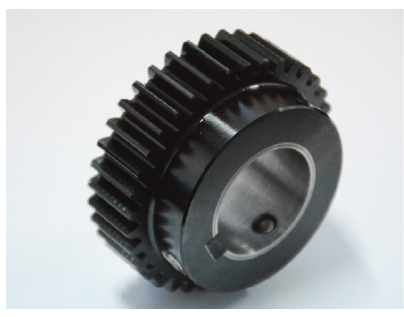

(d)

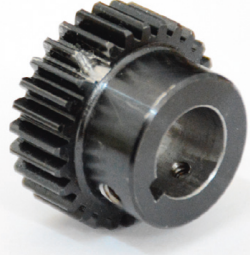

(b)

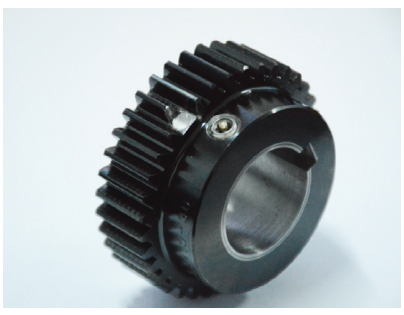

(e)

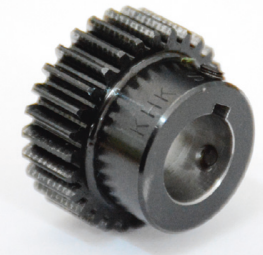

(c)

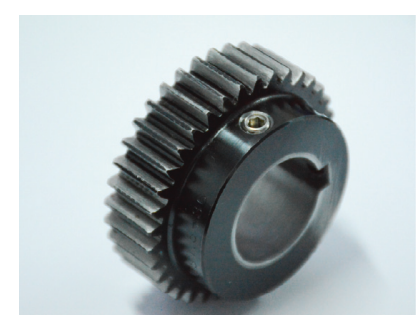

(f)

Figure 4: Physical diagram of faulty sun and spur gears: (a) normal sun gear, (b) local fault (broken tooth) of sun gear, (c) distributed fault (uniform wear) of sun gear, (d) normal spur gear, (e) local fault (broken tooth) of spur gear, and (f) distributed fault (uniform wear) of spur gear.

TABLE 3: Rotation frequencies of the gears at each stage and characteristic frequencies of the faulty gears.

\begin{tabular}{|c|c|c|c|c|c|c|c|c|c|c|}
\hline \multirow[b]{2}{*}{ Parameter } & \multicolumn{4}{|c|}{ First-stage planetary gear } & \multicolumn{3}{|c|}{ Second-stage spur gear } & \multicolumn{3}{|c|}{ Third-stage spur gear } \\
\hline & $\begin{array}{l}\text { Sun } \\
\text { gear }\end{array}$ & $\begin{array}{l}\text { Planet } \\
\text { gear }\end{array}$ & $\begin{array}{l}\text { Planet } \\
\text { carrier }\end{array}$ & $\begin{array}{l}\text { Meshing } \\
\text { frequency }\end{array}$ & $\begin{array}{l}\text { Driving } \\
\text { gear }\end{array}$ & $\begin{array}{l}\text { Driven } \\
\text { gear }\end{array}$ & $\begin{array}{l}\text { Meshing } \\
\text { frequency }\end{array}$ & $\begin{array}{l}\text { Driving } \\
\text { gear }\end{array}$ & $\begin{array}{c}\text { Driven } \\
\text { gear }\end{array}$ & $\begin{array}{l}\text { Meshing } \\
\text { frequency }\end{array}$ \\
\hline Rotation frequency & 29.63 & 18.02 & 6.48 & 648.59 & 6.48 & 1.88 & 188.09 & 1.88 & 0.75 & 67.71 \\
\hline $\begin{array}{l}\text { Characteristic frequency of } \\
\text { local fault }\end{array}$ & 92.64 & $\begin{array}{l}18.02 \\
36.04\end{array}$ & - & - & 6.48 & 1.88 & - & 1.88 & 0.75 & - \\
\hline $\begin{array}{l}\text { Characteristic frequency of } \\
\text { distributed fault }\end{array}$ & 23.16 & 18.02 & - & - & 188.09 & 188.09 & - & 67.71 & 67.71 & - \\
\hline
\end{tabular}

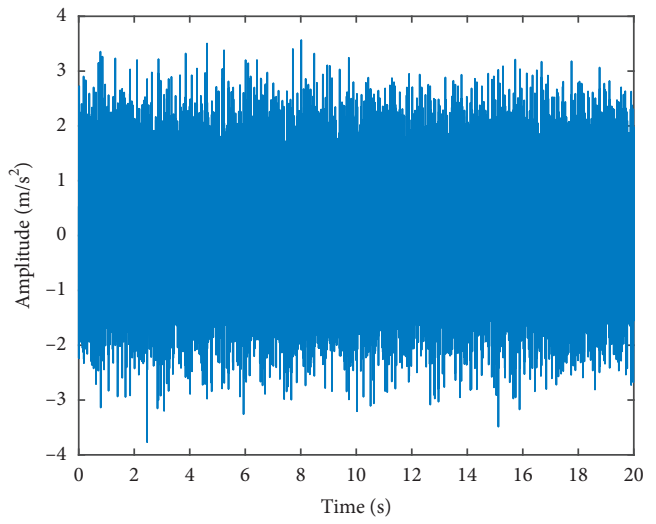

(a)

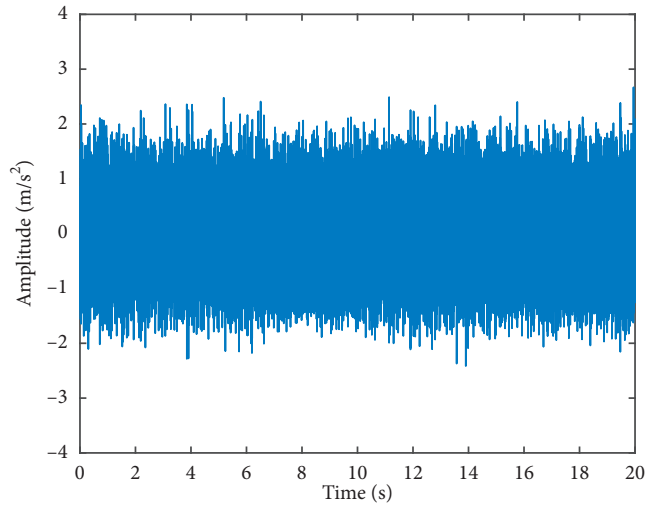

(b)

FIgURE 5: Continued. 


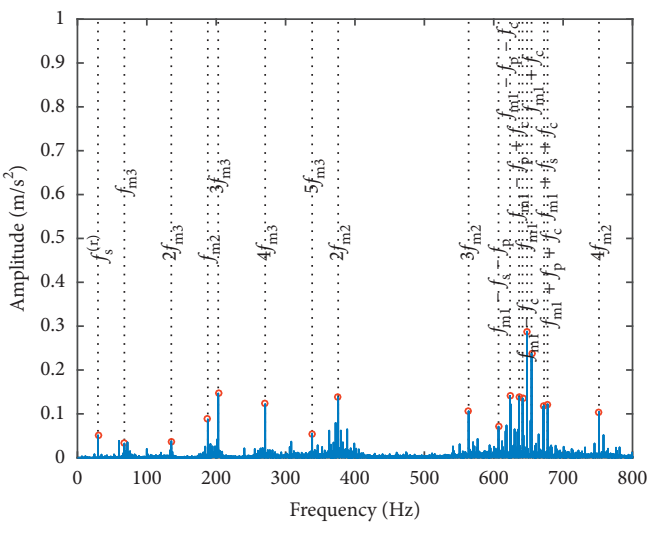

(c)
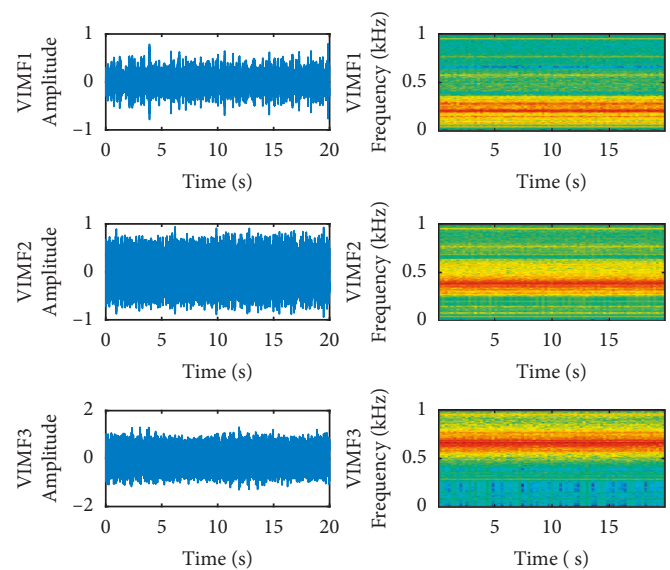

(e)

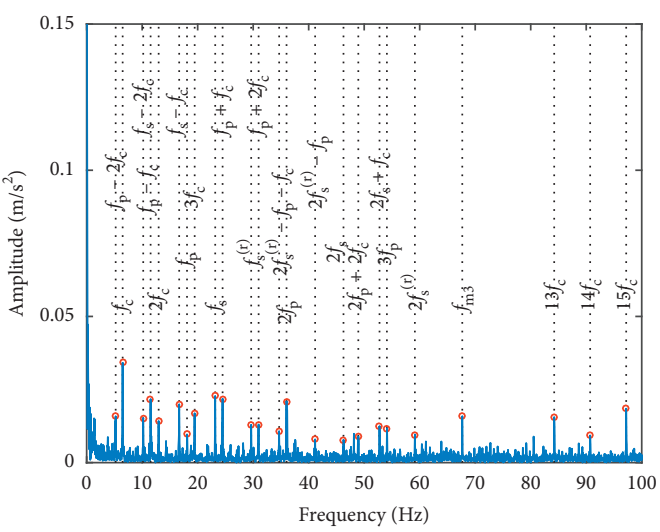

(d)

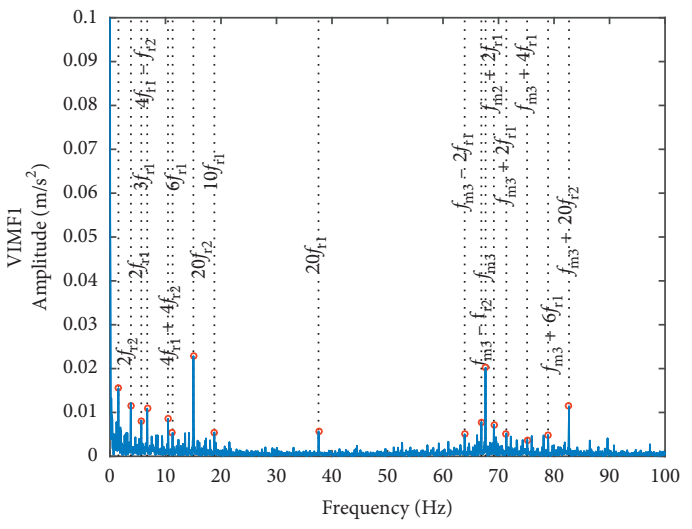

(f)

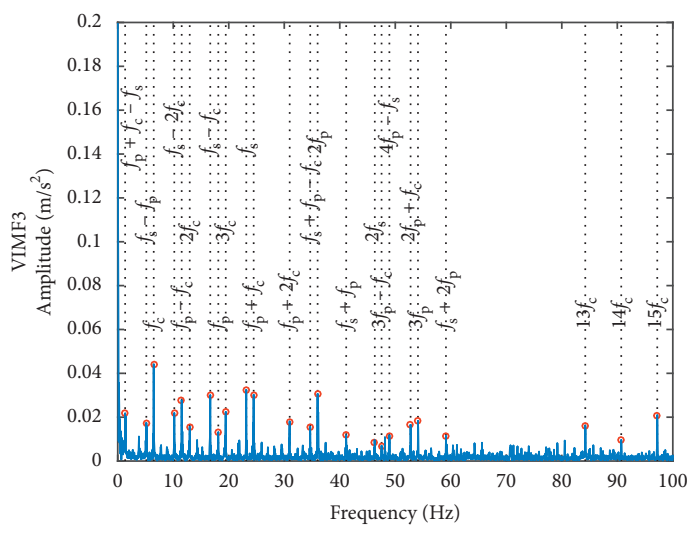

(g)

FIGURE 5: Normal vibration signal analysis: (a) time-domain waveform of original vibration signal, (b) time-domain waveform of filtered vibration signal, (c) spectrum of filtered vibration signal, (d) envelope spectrum of filtered vibration signal, (e) time-domain and timefrequency VMD decomposition images, (f) envelope of VIMF1, and (g) envelope of VIMF3.

5.2.2. Sun Gear Broken Teeth-Spur Gear Broken Teeth. Figure 6 presents the vibration signal analysis results obtained when both the sun gear of the planetary gear and the driving third-stage spur gear had broken teeth simultaneously. The fault characteristic frequency of the sun gear is $4 f_{\mathrm{s}}$ and that of the spur gear is $f_{\mathrm{r} 1}$.

The spectrogram of the vibration signal (Figure 6(b)) shows that some continuous peaks occur between the meshing frequency of the third-stage spur gear $\left(f_{\mathrm{m} 3}\right)$ and four times that frequency $\left(4 f_{\mathrm{m} 3}\right)$, because of the broken teeth of the spur gear. However, these peaks are not prominent. Some sidebands appear near the meshing frequency $\left(f_{\mathrm{m} 1}\right)$ of the planetary gear, including at the combinatorial frequency between the meshing frequency of the planetary gear and the sun gear fault characteristic frequency. In addition, there are the combinatorial frequencies $\left(f_{\mathrm{m} 1} \pm 2 f_{\mathrm{s}} \pm f_{\mathrm{p}}, f_{\mathrm{m} 1}-f_{\mathrm{s}}, f_{\mathrm{m} 1}+3 f_{\mathrm{s}}, f_{\mathrm{m} 1} \pm 5 f_{\mathrm{s}}, f_{\mathrm{m} 1}+\right.$ $5 f_{\mathrm{s}}+f_{\mathrm{c}}$ ) between the meshing frequency of the planetary 

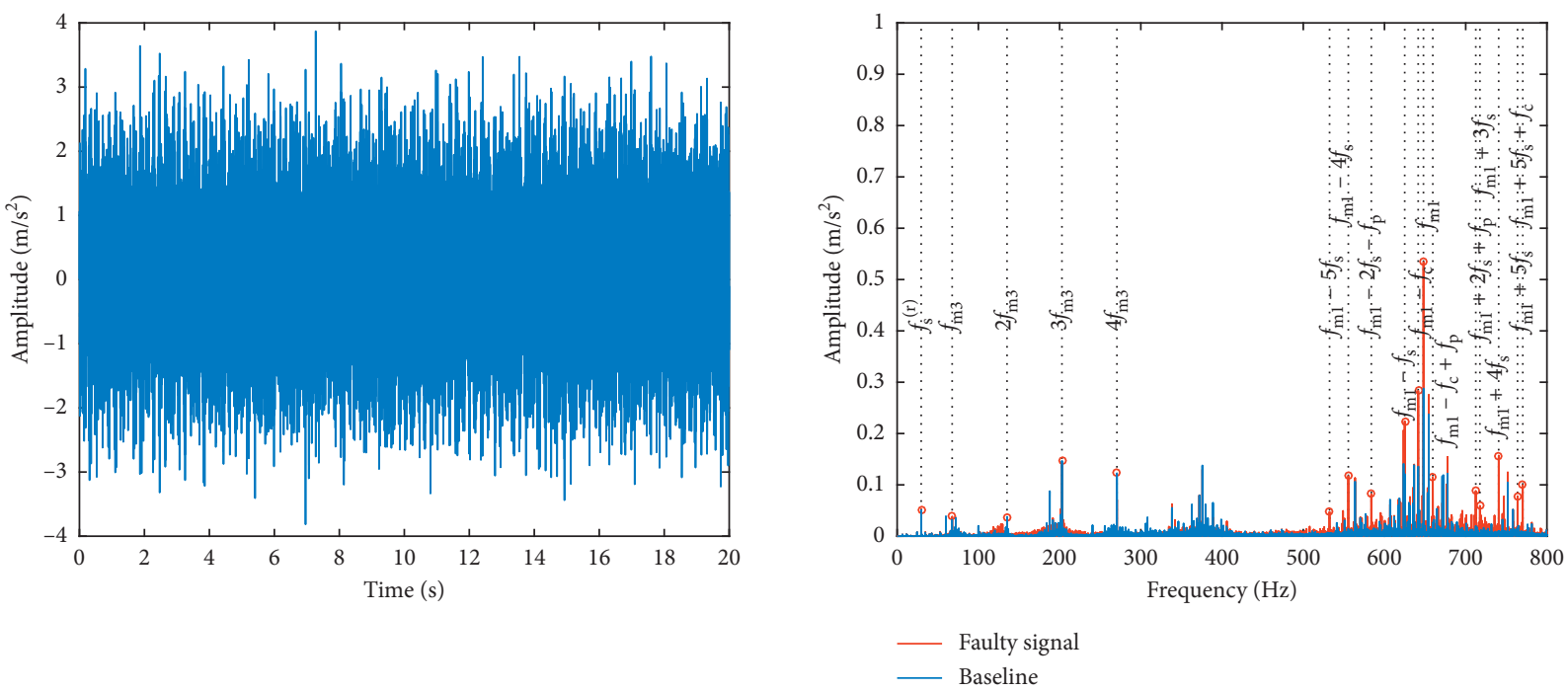

(a)

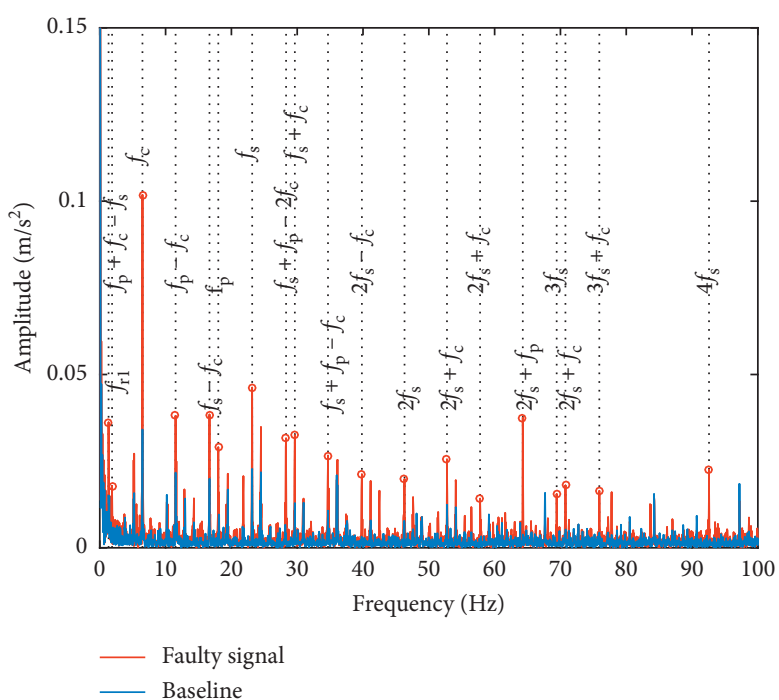

(b)
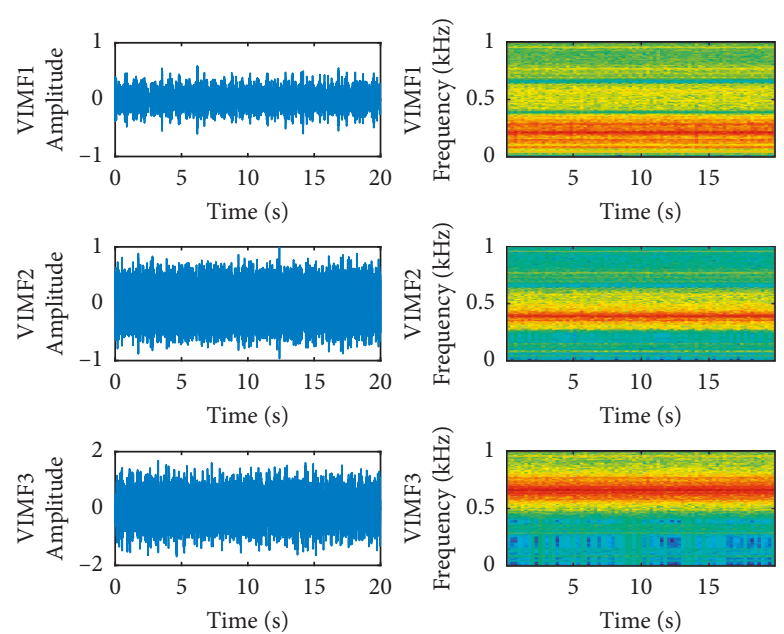

(c)

(d)

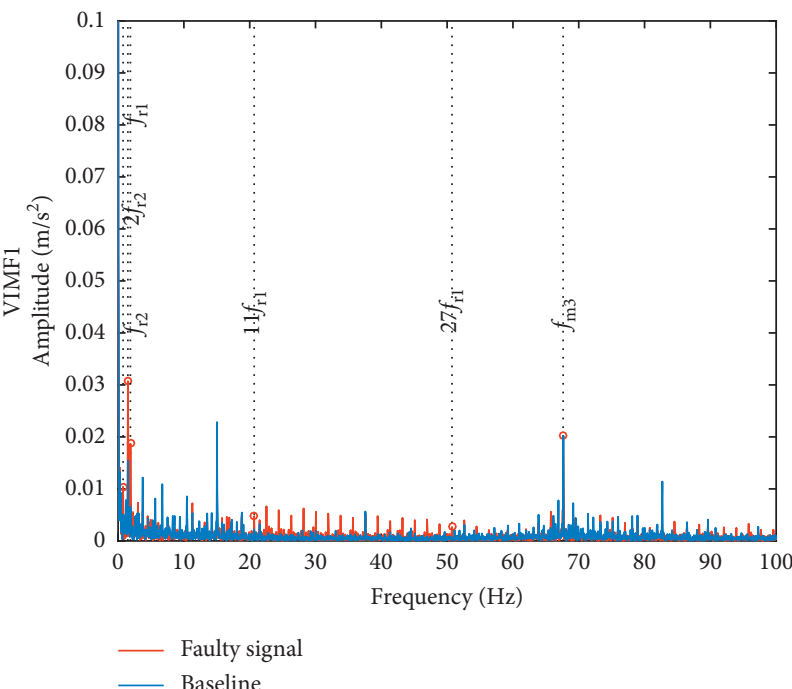

(e)

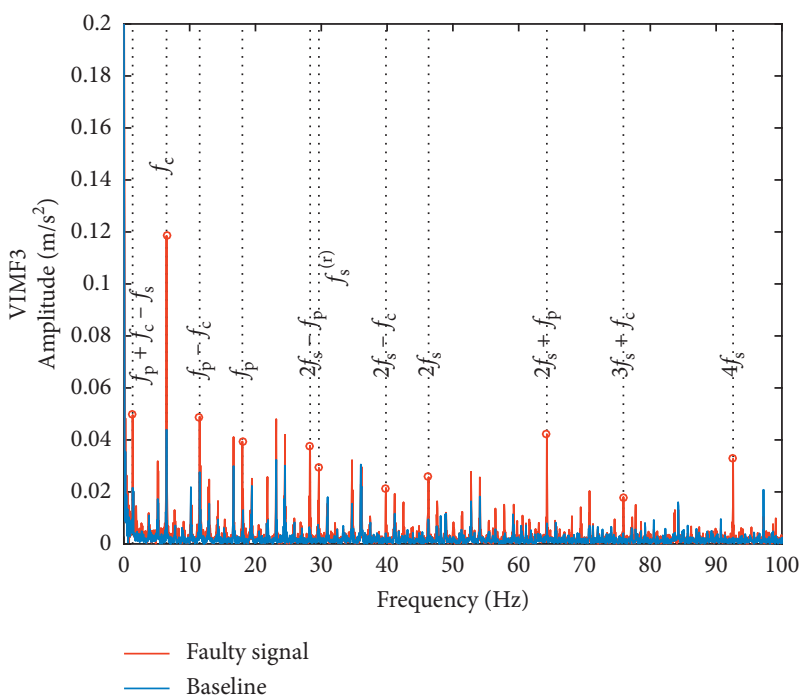

(f)

FIGURE 6: Sun and spur gear broken tooth analysis results: (a) time-domain waveform of filtered vibration signal, (b) spectrum of filtered vibration signal, (c) envelope spectrum of filtered vibration signal, (d) time-domain and time-frequency VMD decomposition images, (e) envelope of VIMF1, and (f) envelope of VIMF3. 
gear $\left(f_{\mathrm{m} 1}\right)$ and $1 / 4$ times the fault characteristic frequency $\left(n / 4\left(4 f_{s}\right)\right)$. Most likely, because manufacturing and assembly errors are inevitable in a real reducer, the four planet gears that meshed with the sun gear could not have been exactly the same; thus, the impacts of the sun and four planet gears differed. Some frequencies appear in the vibration signal envelope spectrum (Figure 6(c)), such as the sun gear fault characteristic frequency $\left(4 f_{\mathrm{s}}\right)$ and the frequencies associated with it $\left(n / 4\left(4 f_{\mathrm{s}}\right) \pm m f_{\mathrm{p}} \pm k f_{\mathrm{c}}\right)$. However, there is no significant change in the spur gear fault characteristic frequency $\left(f_{r 1}\right)$.

After VMD decomposition, we obtained three VIMFs. Figure 6(d) shows the time-domain and time-frequency results for each one. VIMF1 and VIMF3 mainly contain the vibration information of the spur and planetary gears, respectively. Figure 6(e) shows the envelope spectrum of VIMF1, revealing that the spur gear fault characteristic frequency $\left(f_{\mathrm{r} 1}\right)$ is obviously increased, and the fault characteristic frequencies multiplied times 11-27 are increased as well. Thus, a broken tooth fault occurred in the spur gear. Figure 6(f) shows the envelope spectrum of VIMF3, where it can be seen that the sun gear fault characteristic frequency $\left(4 f_{\mathrm{s}}\right)$ is obviously increased, and those related to the sun gear fault characteristic frequency $\left(2 f_{\mathrm{s}}, 2 f_{\mathrm{s}} \pm f_{\mathrm{c}}, 2 f_{\mathrm{s}} \pm f_{\mathrm{p}}\right)$ are increased as well. These results indicate that a broken tooth fault occurred in the sun gear.

5.2.3. Sun Gear Wear-Spur Gear Wear. Figure 7 shows the vibration signal analysis results obtained when both the sun gear of the planetary gear and the driving gear of the thirdstage spur gear were worn simultaneously. The fault characteristic frequencies of the sun and spur gears are $f_{\mathrm{s}}$ and $f_{\mathrm{m} 3}$, respectively.

The vibration signal spectrogram (Figure 7(b)) shows that the third-stage spur gear meshing frequency $\left(f_{\mathrm{m} 3}\right)$, as well as two and three times the meshing frequency $\left(2 f_{\mathrm{m} 3}\right.$ and $3 f_{\mathrm{m} 3}$, respectively), is increased slightly. The planetary gear meshing frequency $\left(f_{\mathrm{m} 1}\right)$ has increased, as has the peak of the sideband near the meshing frequency according to the sun gear fault characteristic frequency $\left(f_{\mathrm{s}}\right)$. Some frequencies appear in the vibration signal envelope spectrum, such as the sun gear fault characteristic frequency and its associated frequencies $\left(f_{\mathrm{m} 1} \pm f_{\mathrm{s}} \pm f_{\mathrm{c}}, f_{\mathrm{m} 1}+f_{\mathrm{s}}+f_{\mathrm{p}}-f_{\mathrm{c}}\right.$, $\left.f_{\mathrm{m} 1}+2 f_{\mathrm{s}}+f_{\mathrm{p}}\right)$. These characteristics indicate that the sun gear wear failure was identified, but the spur gear fault diagnosis was not satisfactory.

After VMD decomposition, it can be concluded from Figure 7(d) that VIMF1 and VIMF3 mainly contain the vibration information of the spur and planetary gears, respectively. Figure $7(\mathrm{e})$ shows the envelope spectrum of VIMF1, revealing that the spur gear fault characteristic frequency $\left(f_{\mathrm{m} 3}\right)$ is obviously increased. This feature indicates that wear fault occurred in the spur gear. Figure 7(f) presents the envelope spectrum of VIMF3, showing that the sun gear fault characteristic frequency $\left(f_{\mathrm{s}}\right)$ is obviously increased, as are its related frequencies $\left(2 f_{\mathrm{s}} \pm f_{\mathrm{c}}, f_{\mathrm{s}} \pm f_{\mathrm{p}}\right)$. Thus, a wear fault occurred in the sun gear.
5.2.4. Sun Gear Broken Teeth-Spur Gear Wear. Figure 8 shows the vibration signal analysis results obtained when the sun gear of the planetary gear had broken teeth and the driving gear of the third-stage spur gear was simultaneously worn. The fault characteristic frequencies for the sun and spur gears are $4 f_{\mathrm{s}}$ and $f_{\mathrm{m} 3}$, respectively.

The vibration signal spectrogram (Figure 8(b)) shows that the meshing frequency of the third-stage spur gear $\left(f_{\mathrm{m} 3}\right)$, as well as two and three times that frequency $\left(2 f_{\mathrm{m} 3}\right.$ and $3 f_{\mathrm{m} 3}$, respectively), is increased slightly. There are some sidebands near the planet gear meshing frequency $\left(f_{\mathrm{m} 1}\right)$. It is clear that there is a combination of the sun gear meshing frequency and fault characteristic frequency in the sidebands $\left(f_{\mathrm{m} 1} \pm 4 f_{\mathrm{s}}\right)$. There are combined frequencies of the meshing frequency and $1 / 4$ times the sun gear fault characteristic frequency $\left(n / 4\left(4 f_{s}\right)\right)$ in the sidebands simultaneously $\left(f_{\mathrm{m} 1} \pm 2 f_{\mathrm{s}} \pm f_{\mathrm{p}}, f_{\mathrm{m} 1}-f_{\mathrm{s}}, f_{\mathrm{m} 1}+3 f_{\mathrm{s}}, f_{\mathrm{m} 1}+\right.$ $\left.5 f_{\mathrm{s}}, f_{\mathrm{m} 1}+5 f_{\mathrm{s}}+f_{\mathrm{c}}\right)$.

Some frequencies appear in the vibration signal envelope spectrum (Figure $8(\mathrm{c})$ ), such as the sun gear fault characteristic frequency $\left(4 f_{s}\right)$ and its associated frequencies $\left(n / 4\left(4 f_{\mathrm{s}}\right) \pm m f_{\mathrm{p}} \pm k f_{\mathrm{c}}\right)$. However, there is no significant change in the spur gear fault characteristic frequency.

After VMD decomposition, it can be concluded from Figure $8(\mathrm{~d})$ that VIMF1 and VIMF3 mainly contain the vibration information of the spur and planetary gears, respectively. Figure $8(\mathrm{e})$ shows the envelope spectrum of VIMF1, revealing that the spur gear fault characteristic frequency $\left(f_{\mathrm{m} 3}\right)$ is obviously increased. Thus, a wear fault occurred in the spur gear. Figure 8(f) presents the envelope spectrum of VIMF3, showing that the sun gear fault characteristic frequency $\left(4 f_{\mathrm{s}}\right)$ and its related frequencies $\left(2 f_{\mathrm{s}}\right.$, $\left.2 f_{\mathrm{s}} \pm f_{\mathrm{c}}, 2 f_{\mathrm{s}} \pm f_{\mathrm{p}}\right)$ are increased. Thus, a broken teeth fault occurred in the sun gear.

\subsubsection{Sun Gear Wear-Spur Gear Broken Teeth. Figure 9} shows the vibration signal analysis results obtained when the sun gear of the planetary gear was worn and the driving gear of the third-stage spur gear simultaneously had broken teeth. The fault characteristic frequencies of the sun and spur gears are $f_{\mathrm{s}}$ and $f_{\mathrm{r} 1}$, respectively.

The vibration signal spectrogram (Figure 9(b)) shows that some continuous peaks occur between the meshing frequency of the third-stage spur gear $\left(f_{\mathrm{m} 3}\right)$ and four times that frequency $\left(4 f_{\mathrm{m} 3}\right)$, because of the broken teeth of the spur gear. However, these peaks are not prominent. The planetary gear meshing frequency $\left(f_{\mathrm{m} 1}\right)$ exhibits a certain increase, and the peaks in the sideband associated with the sun gear fault characteristic frequency $\left(f_{\mathrm{m} 1} \pm f_{\mathrm{s}}-f_{\mathrm{c}}\right.$, $\left.f_{\mathrm{m} 1} \pm f_{\mathrm{p}}-f_{\mathrm{c}}, f_{\mathrm{m} 1}+f_{\mathrm{s}}+f_{\mathrm{p}}-f_{\mathrm{c}}, f_{\mathrm{m} 1}+2 f_{\mathrm{s}}+f_{\mathrm{p}}\right)$ are increased as well. The vibration signal envelope spectrum (Figure 9(c)) clearly reveals that the fault characteristic frequency $\left(f_{\mathrm{s}}\right)$ and the frequencies associated with it $\left(f_{\mathrm{s}} \pm f_{\mathrm{c}}, 2 f_{\mathrm{s}}-f_{\mathrm{c}}, 2 f_{\mathrm{s}}+2 f_{\mathrm{c}}-f_{\mathrm{p}}, 2 f_{\mathrm{s}}+f_{\mathrm{p}}-f_{\mathrm{c}}\right)$ are increased. These features indicate that wear failure occurred on the sun gear, but the spur gear fault diagnosis is not ideal.

After VMD decomposition, it can be concluded from Figure 9(d) that VIMF1 and VIMF3 mainly contain the 

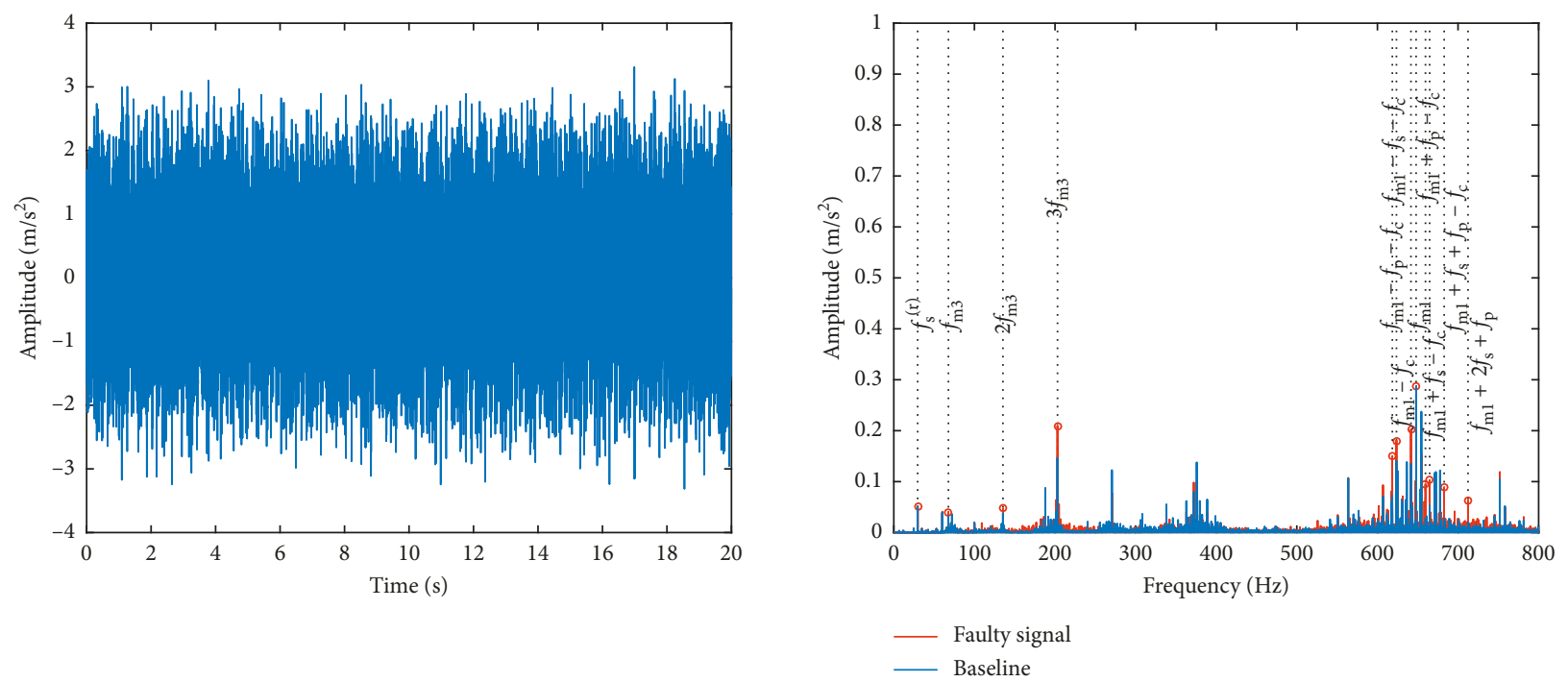

(a)

(b)
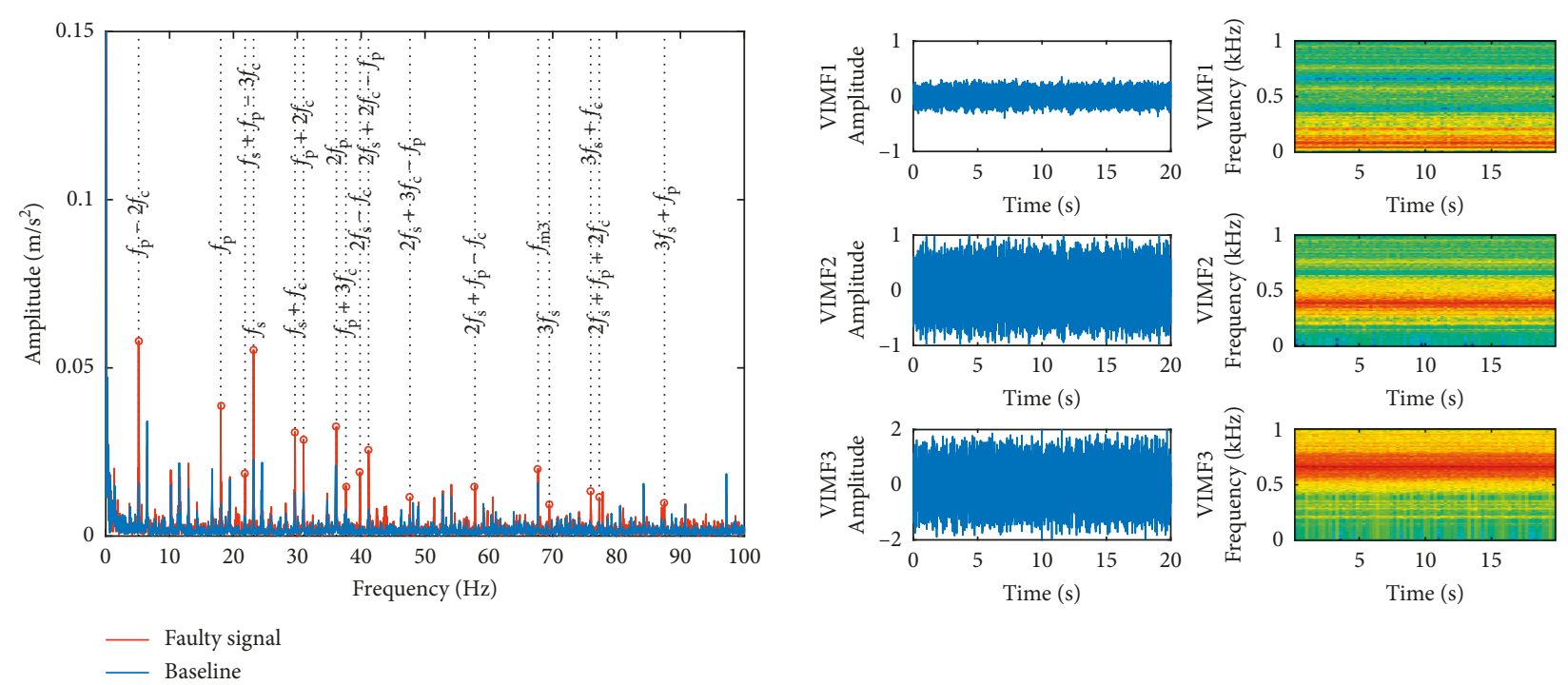

(c)

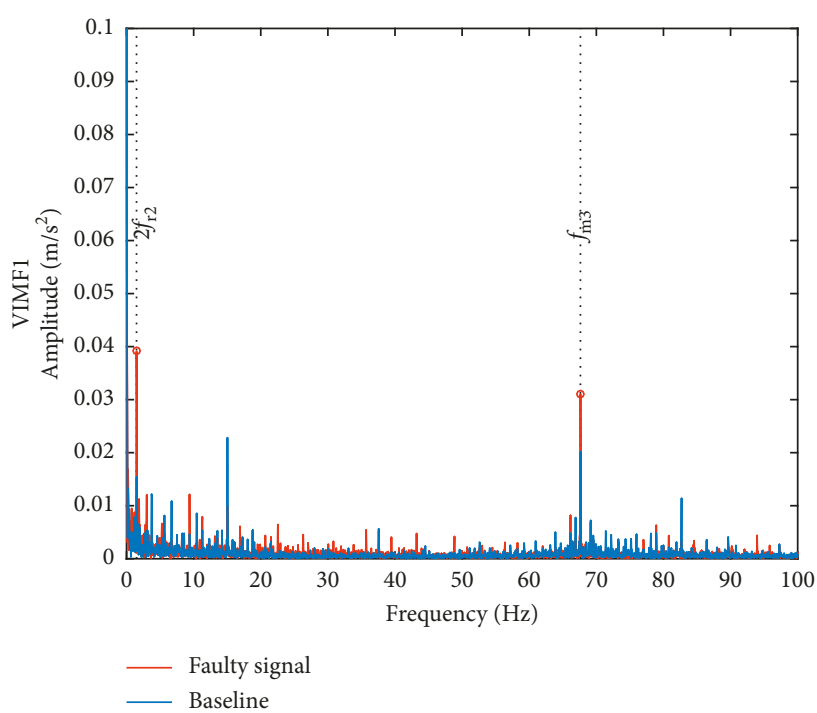

(e)

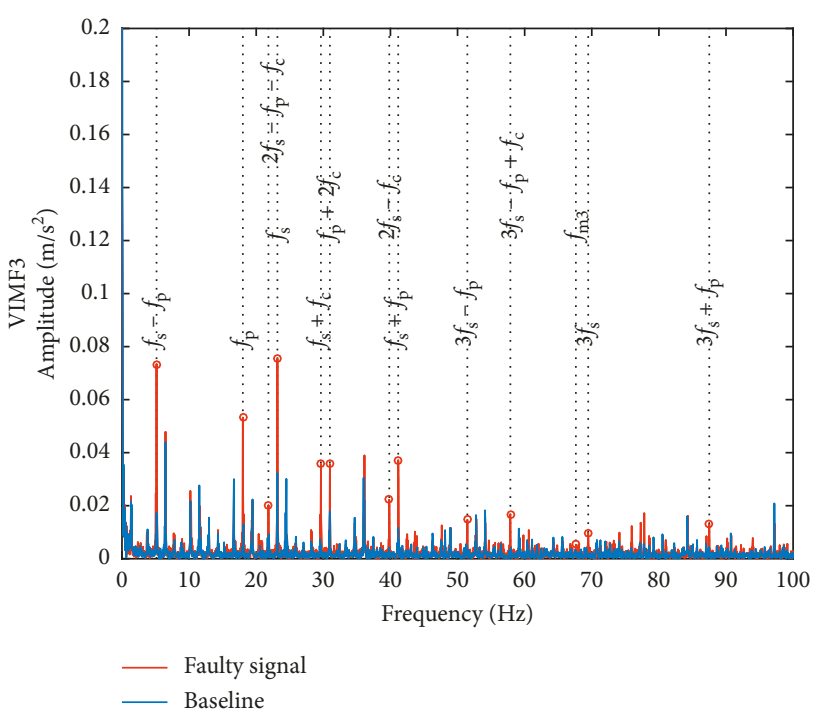

(f)

FIGURE 7: Sun and spur gear wear analysis results: (a) time-domain waveform of filtered vibration signal, (b) spectrum of filtered vibration signal, (c) envelope spectrum of filtered vibration signal, (d) time-domain and time-frequency VMD decomposition images, (e) envelope of VIMF1, and (f) envelope of VIMF3. 

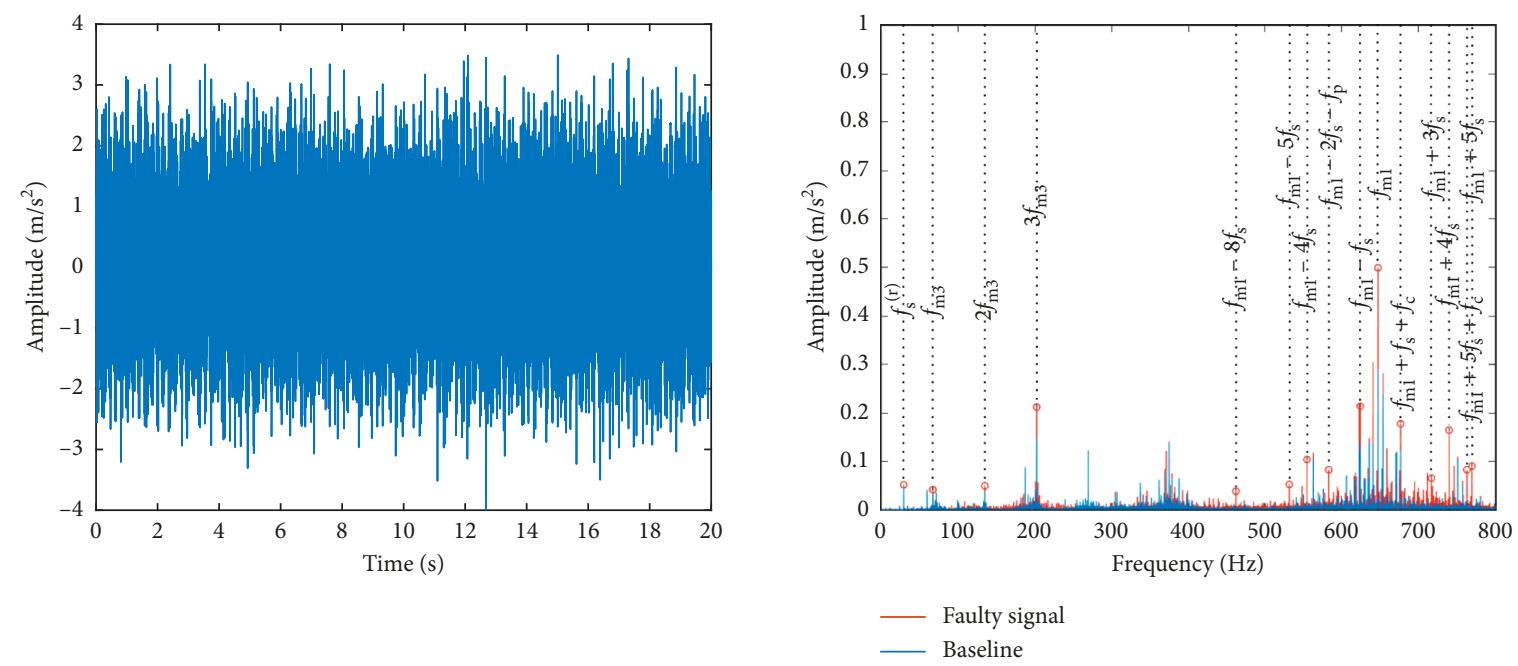

(a)

(b)
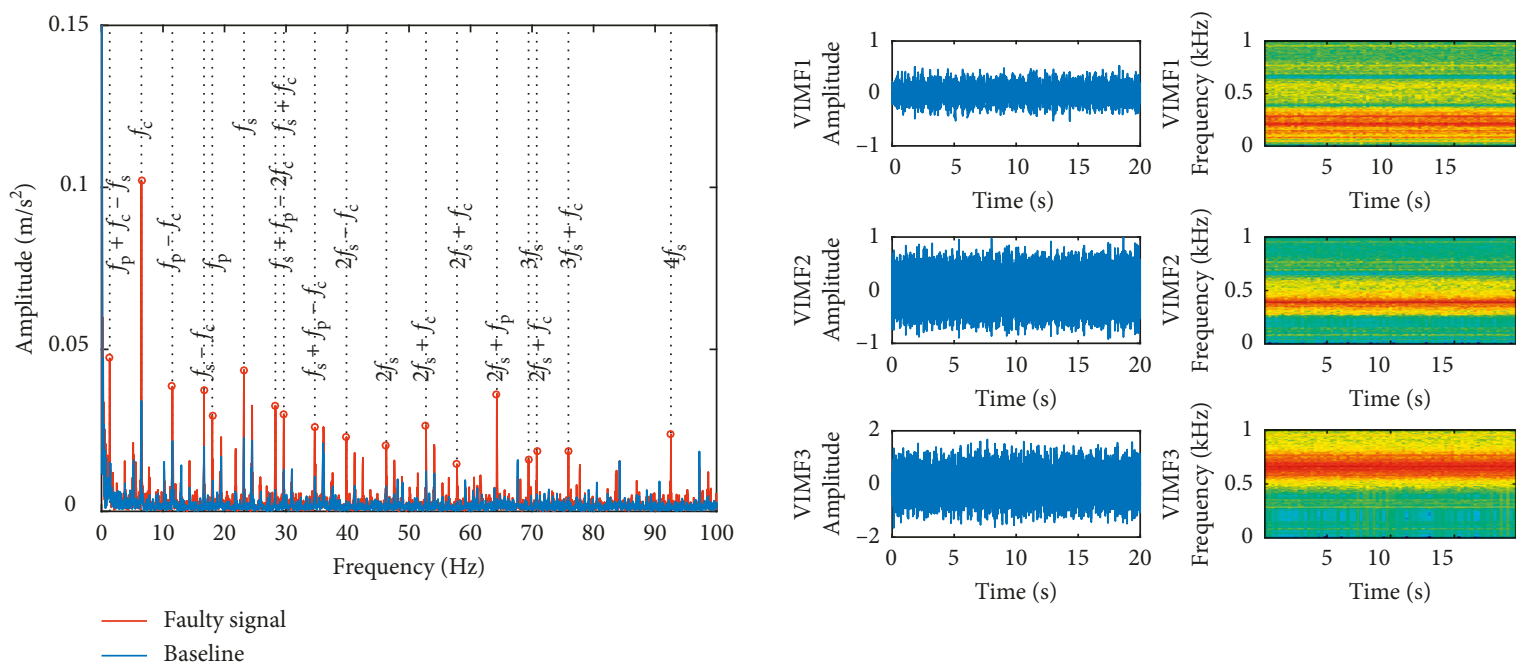

(c)

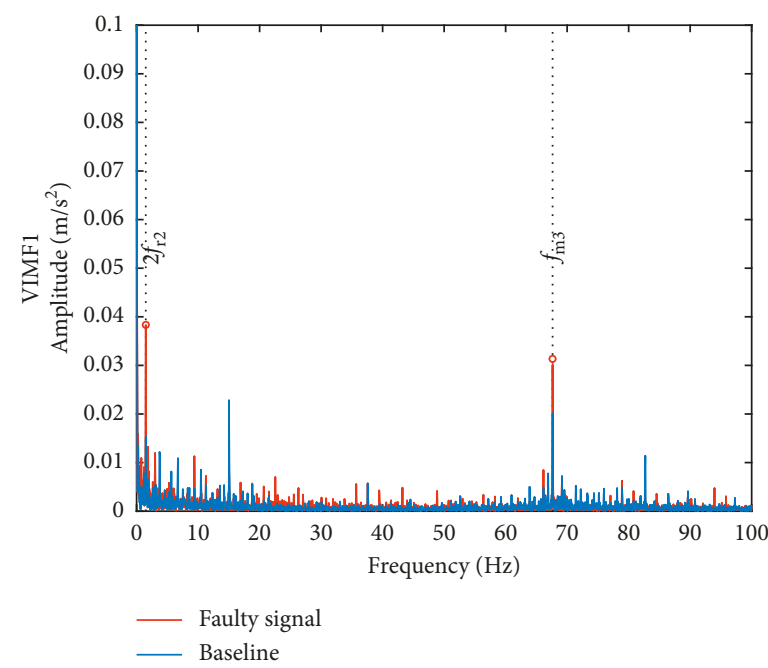

(d)

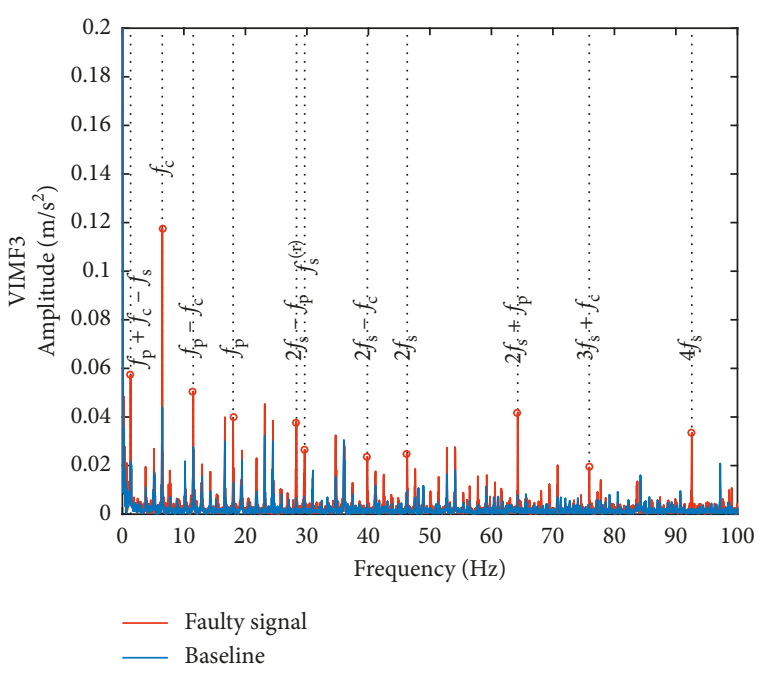

(e)

(f)

FIGURE 8: Analysis results for sun gear with broken teeth and worn spur gear: (a) time-domain waveform of filtered vibration signal, (b) spectrum of filtered vibration signal, (c) envelope spectrum of filtered vibration signal, (d) time-domain and time-frequency VMD decomposition images, (e) envelope of VIMF1, and (f) envelope of VIMF3. 

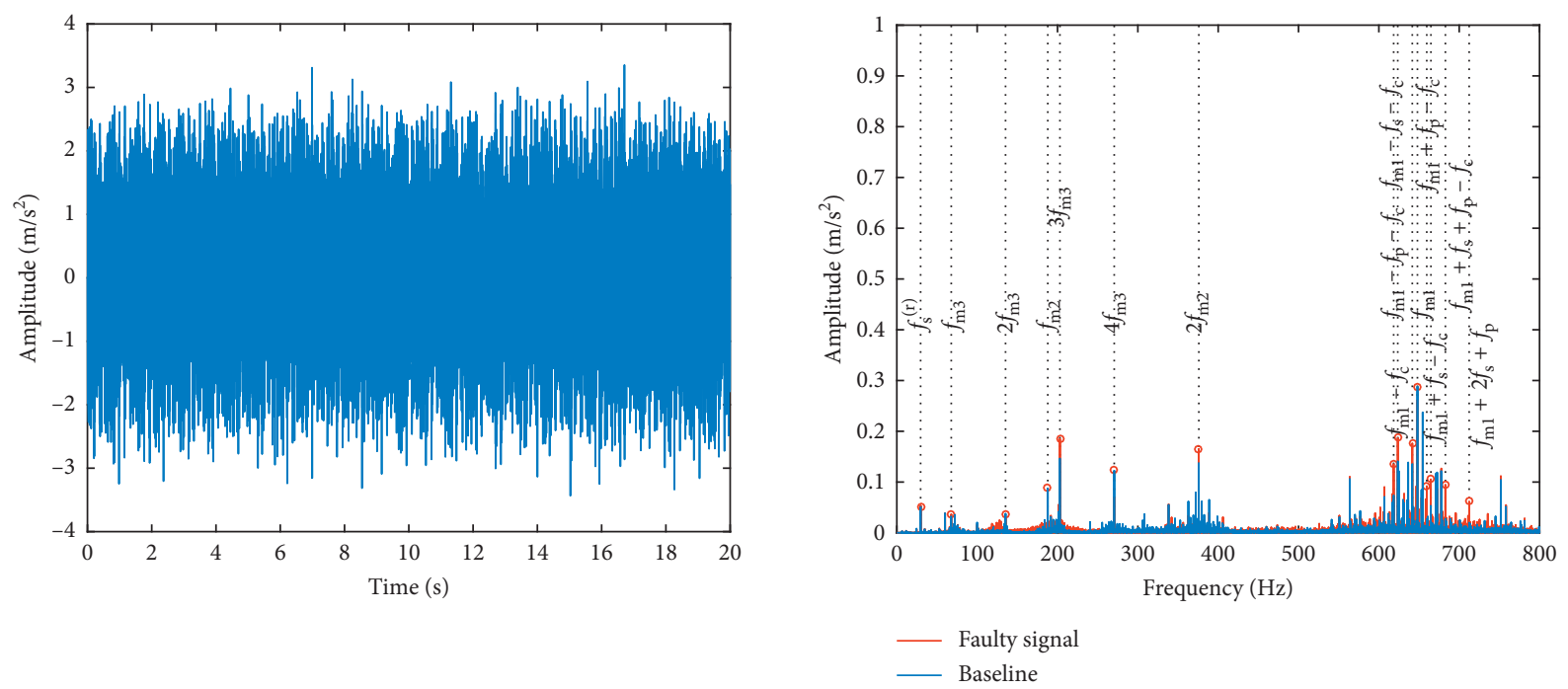

(a)

(b)
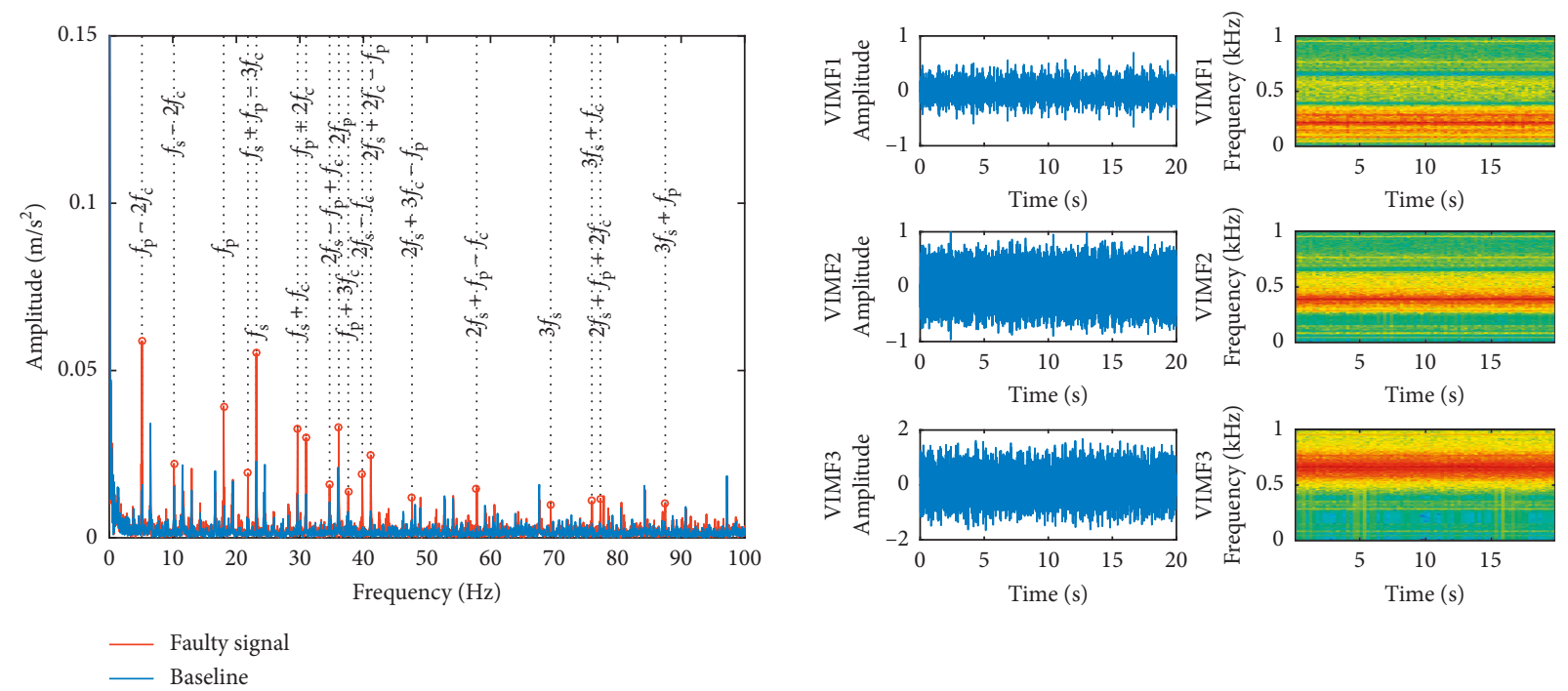

(c)

(d)

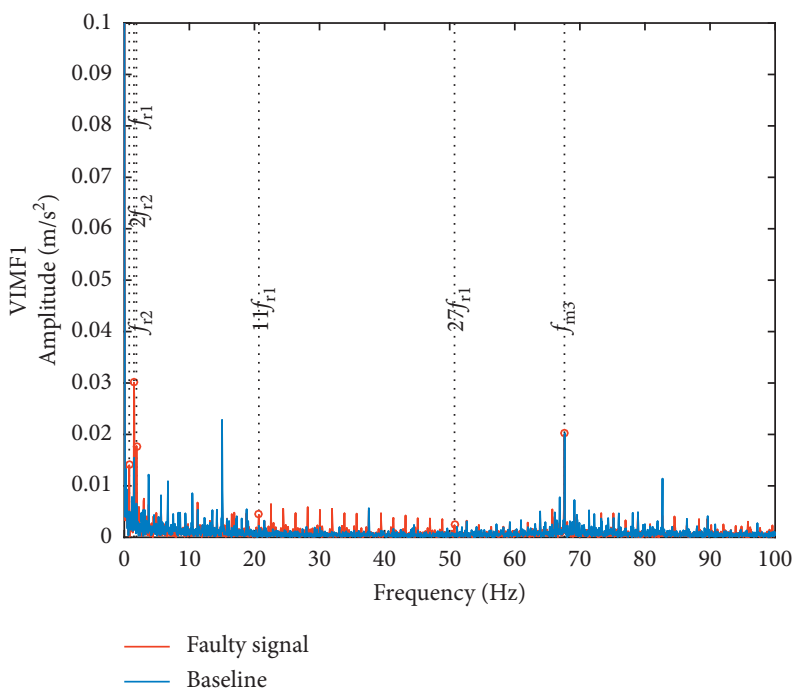

(e)

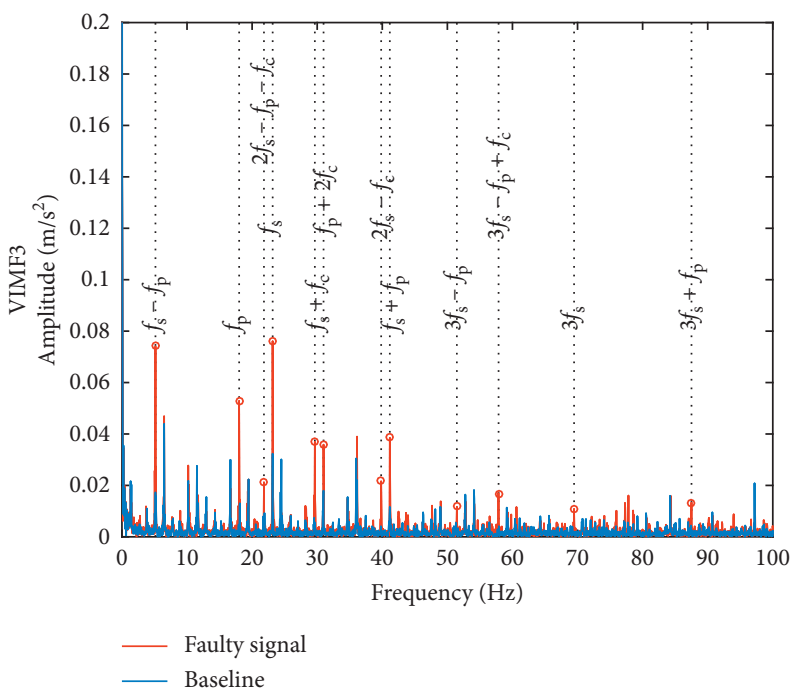

(f)

Figure 9: Analysis results for worn sun gear and spur gear with broken teeth: (a) time-domain waveform of filtered vibration signal, (b) spectrum of filtered vibration signal, (c) envelope spectrum of filtered vibration signal, (d) time-domain and time-frequency VMD decomposition images, (e) envelope of VIMF1, and (f) envelope of VIMF3. 
vibration information of the spur and planetary gears, respectively. Figure 9(e) depicts the envelope spectrum of VIMF1, showing that the spur gear fault characteristic frequency $\left(f_{\mathrm{rl}}\right)$ is obviously increased and 11-27 times that frequency are increased as well. Thus, a broken tooth fault occurred in the spur gear. Figure 9(f) presents the envelope spectrum of VIMF3, revealing that the sun gear fault characteristic frequency $\left(f_{\mathrm{s}}\right)$ is obviously increased, as are the frequencies related to it $\left(f_{\mathrm{s}}+f_{\mathrm{c}}, 2 f_{\mathrm{s}}-f_{\mathrm{c}}, f_{\mathrm{s}} \pm f_{\mathrm{p}}\right.$, $\left.3 f_{\mathrm{s}}-f_{\mathrm{p}}+f_{\mathrm{c}}\right)$. Thus, a wear fault occurred in the sun gear.

\section{Discussion}

In the analysis results of the simulation signal, we could effectively extract the desired fault characteristic frequencies of the gears. However, the frequencies distribution of the simulation signal is simpler than the actual vibration signal because our focus is only on the ideal situation. We only considered the meshing frequency of all gears, the rotation frequency of the planet carrier, and the fault characteristic frequencies of the sun and spur gears. Although these are somewhat different from the actual situation, they sufficiently demonstrate the effectiveness of the proposed method.

When the reducer is running normally, assembly and machining errors are unavoidable, the planet gears are not exactly the same, and there are many other transmission paths for the vibration signal. Further, the gear meshing transmission has periodic fluctuations that can trigger the related vibration. Thus, the actual vibration signal is complex, and it is therefore reasonable that there are some frequencies in the spectrum figures.

When multiple faults occur in a multistage reducer, peaks in the VIMF envelope spectra do not appear at the fault characteristic frequencies of the gears and their harmonics, most likely because of manufacturing and assembling errors that are inevitable in actual multistage reducers. Therefore, it is reasonable to see other peaks in VIMF envelope spectra. The desired fault characteristic frequency of the gear can be obtained based on the envelope spectra of VIMF1 and VIMF3. Therefore, it is possible to diagnose planetary and spur gear failures by employing the proposed method.

To diagnose multiple faults in a multistage reducer, we proposed a method based on amplitude and frequency demodulation. In multistage reducer box vibration signal analysis of the spectrum and envelope spectrum directly, the spur gear fault characteristics are not obvious because its vibration energy is smaller than the vibration energy of the planetary gear. To recognize a spur gear fault, it is necessary to separate the spur gear vibration signal from that of the multistage reducer box. In a multistage reducer, the meshing frequencies of the gear stages are often in different frequency bands because of deceleration or acceleration. Therefore, the vibration signal of a multistage reducer box can be decomposed by frequency band, such that each frequency band contains the vibration information of different levels of gears. The VMD method can facilitate signal decomposition according to the expected frequency band, and the number of layers decomposed is manageable. To validate fully the effectiveness of the proposed method, we analyzed four different laboratory signals in a multistage reducer, where the sun gear of the planetary gear and the spur gear experienced local faults (broken teeth) or distributed faults (uniform wear). The experimental multistage reducer vibration signals were composed of various components generated by the planetary gear, spur gear, bearings, input/output shafts, and connected devices such as motors. They have the same multicomponent nature as those of a real industrial multistage reducer. Thus, they were sufficient to test the performance of the VMD demodulation method. The analysis results obtained using the four different datasets were all in line with our expectations.

We used VMD to decompose the vibration signals according to frequency band. The spur and planetary gear vibration information was included in VIMF1 and VIMF3, respectively, so their gear fault characteristic frequencies could clearly be seen in the corresponding envelope spectra. The experimental validation demonstrates the effectiveness of the proposed method and its potential for use in in-situ applications.

\section{Conclusions}

To address fault characteristic frequency extraction when multiple faults occur simultaneously in a multistage reducer, we proposed a joint amplitude and frequency demodulation method to identify the characteristic frequencies of faulty gears in multistage reducer systems more effectively. In this technique, VMD is employed to decompose the signal into VIMFs such that each VIMF contains the vibration information of a gear stage. Then, the envelope spectrum of the VIMF of interest is calculated, and the gear faults are identified by the fault characteristic frequency peaks in the envelope spectra. The method was demonstrated by conducting simulated signal analysis, and its performance was validated experimentally using four experimental signals. In future work, we will collect industrial multistage reducer vibration datasets to validate the proposed method further. Throughout this study, we assumed that the multistage reducer rotation speed was constant. We are currently doing research to address this issue when the rotation speed fluctuates.

\section{Data Availability}

We cannot share the data because our project has not yet been completed.

\section{Conflicts of Interest}

The authors declare that they have no conflicts of interest.

\section{Acknowledgments}

This paper is supported by the National Natural Science Foundation of China (no. 51475318) and the Innovation Project in Postgraduate Education of Shanxi Province (no. 2016BY058). The authors are grateful to the anonymous 
reviewers for their valuable and detailed comments and suggestions, which have helped to improve this paper.

\section{References}

[1] Y. Lei, J. Lin, M. J. Zuo, and Z. He, "Condition monitoring and fault diagnosis of planetary gearboxes: a review," Measurement, vol. 48, no. 1, pp. 292-305, 2014.

[2] X. Zhang, L. Wang, and Q. Miao, "Fault diagnosis techniques for planetary gearboxes under variable conditions: a review," in Proceedings of Prognostics and System Health Management Conference, pp. 1-11, IEEE, Harbin, China, July 2017.

[3] V. K. Ambarisha and R. G. Parker, "Nonlinear dynamics of planetary gears using analytical and finite element models," Journal of Sound \& Vibration, vol. 302, no. 3, pp. 577-595, 2007.

[4] C. Li and M. Liang, "Time-frequency signal analysis for gearbox fault diagnosis using a generalized synchrosqueezing transform," Mechanical Systems \& Signal Processing, vol. 26, no. 1, pp. 205-217, 2012.

[5] W. J. Wang and P. D. McFadden, "Application of wavelets to gearbox vibration signals for fault detection," Journal of Sound \& Vibration, vol. 192, no. 5, pp. 927-939, 1996.

[6] D. Cao, J. Kang, J. Zhao, and X. Zhang, "Fault diagnosis of gearbox based on EEMD and HMM," in Proceedings of Prognostics and System Health Management, pp. 1-9, IEEE, Beijing, China, May 2012.

[7] H. Pan, Q. Ma, and X. Wei, "Research on fault diagnosis of gearbox based on particle swarm optimization algorithm," in Proceedings of IEEE International Conference on Mechatronics, pp. 32-37, IEEE, Budapest, Hungary, July 2006.

[8] Y. Lei, D. Han, J. Lin, and Z. He, "Planetary gearbox fault diagnosis using an adaptive stochastic resonance method," Mechanical Systems and Signal Processing, vol. 38, no. 1, pp. 113-124, 2013.

[9] W. Bartelmus and R. Zimroz, "A new feature for monitoring the condition of gearboxes in non-stationary operating conditions," Mechanical Systems and Signal Processing, vol. 23, no. 5, pp. 1528-1534, 2009.

[10] P. D. McFadden, "A technique for calculating the time domain averages of the vibration of the individual planet gears and the sun gear in an epicyclic gearbox," Journal of Sound \& Vibration, vol. 144, no. 1, pp. 163-172, 1991.

[11] P. D. McFadden, "Window functions for the calculation of the time domain averages of the vibration of the individual planet gears and sun gear in an epicyclic gearbox," Mechanisms of Development, vol. 97, no. 1-2, pp. 93-104, 1994.

[12] P. D. Samuel and D. J. Pines, "Vibration separation methodology for planetary gear health monitoring," in Proceedings of Smart Structures and Materials 2000: Smart Structures and Integrated Systems, vol. 3985, pp. 250-260, San Diego, CA, USA, March 2000.

[13] T. Barszcz and R. B. Randall, "Application of spectral kurtosis for detection of a tooth crack in the planetary gear of a wind turbine," Mechanical Systems and Signal Processing, vol. 23, no. 4, pp. 1352-1365, 2009.

[14] B. Zhang, T. Khawaja, R. Patrick, G. Vachtsevanos, M. Orchard, and A. Saxena, "A novel blind deconvolution denoising scheme in failure prognosis," Transactions of the Institute of Measurement and Control, vol. 32, no. 1, pp. 561-566, 2007.

[15] B. Zhang, T. Khawaja, R. Patrick et al., "Application of blind deconvolution denoising in failure prognosis," IEEE
Transactions on Instrumentation \& Measurement, vol. 58, no. 2, pp. 303-310, 2009.

[16] X. Chen and Z. Feng, "Application of reassigned wavelet scalogram in wind turbine planetary gearbox fault diagnosis under nonstationary conditions," Shock and Vibration, vol. 2016, Article ID 6723267, 12 pages, 2016.

[17] Z. Feng and M. Liang, "Complex signal analysis for wind turbine planetary gearbox fault diagnosis via iterative atomic decomposition thresholding," Journal of Sound \& Vibration, vol. 333, no. 20, pp. 5196-5211, 2014.

[18] Z. Feng, M. Liang, Y. Zhang, and S. Hou, "Fault diagnosis for wind turbine planetary gearboxes via demodulation analysis based on ensemble empirical mode decomposition and energy separation," Renewable Energy, vol. 47, no. 1, pp. 112-126, 2012.

[19] Z. Feng and S. F. Qin, "Planetary gearbox fault diagnosis based on Hilbert vibration decomposition and higher order differential energy operator," Journal of Vibration \& Shock, vol. 35, no. 5, pp. 47-54, 2016.

[20] Z. Feng, M. J. Zuo, J. Qu, T. Tian, and Z. Liu, “Joint amplitude and frequency demodulation analysis based on local mean decomposition for fault diagnosis of planetary gearboxes," Mechanical Systems and Signal Processing, vol. 40, no. 1, pp. 56-75, 2013.

[21] J. Lin and Q. Chen, "Application of the EEMD method to multiple faults diagnosis of gearbox," in Proceedings of International Conference on Advanced Computer Control, pp. 395-399, IEEE, Shenyang, China, 2010.

[22] W. Teng, X. Ding, X. Zhang, Y. Liu, and Z. Ma, "Multi-fault detection and failure analysis of wind turbine gearbox using complex wavelet transform," Renewable Energy, vol. 93, pp. 591-598, 2016.

[23] D. Zhang and D. Yu, "Multi-fault diagnosis of gearbox based on resonance-based signal sparse decomposition and comb filter," Measurement, vol. 103, pp. 361-369, 2017.

[24] Y. Kanda, T. Saka, M. Fujikawa, K. Ando, I. Sako, and I. Kawahara, "Experimental transfer path analysis of gear whine," in Proceedings of SAE 2005 Noise and Vibration Conference and Exhibition, SAE Technical Paper 2005-012288, Long Beach, CA, USA, 2005.

[25] Z. Feng and M. J. Zuo, "Vibration signal models for fault diagnosis of planetary gearboxes," Journal of Sound \& Vibration, vol. 331, no. 22, pp. 4919-4939, 2012.

[26] F. Chaari, W. Bartelmus, R. Zimroz, T. Fakhfakh, and M. Haddar, "Gearbox vibration signal amplitude and frequency modulation," Shock and Vibration, vol. 19, no. 4, pp. 635-652, 2012.

[27] F. K. Omar, K. A. Moustafa, and S. Emam, "Mathematical modeling of gearbox including defects with experimental verification," Journal of Vibration \& Control, vol. 18, no. 9, pp. 1310-1321, 2011.

[28] P. D. McFadden and J. D. Smith, "An explanation for the asymmetry of the modulation sidebands about the tooth meshing frequency in epicyclic gear vibration," Proceedings of the Institution of Mechanical Engineers Part C Journal of Mechanical Engineering Science, vol. 199, no. 13, pp. 65-70, 1985.

[29] J. McNames, "Fourier series analysis of epicyclic gearbox vibration," Journal of Vibration and Acoustics, vol. 124, no. 1, pp. 150-152, 2002.

[30] M. Mosher, "Understanding vibration spectra of planetary gear systems for fault detection," in Proceedings of 2003 International Design Engineering Technical Conferences and Computers and Information in Engineering Conference, 
pp. 645-652, American Society of Mechanical Engineers, Chicago, IL, USA, September 2003.

[31] M. Inalpolat and A. Kahraman, "A theoretical and experimental investigation of modulation sidebands of planetary gear sets," Journal of Sound \& Vibration, vol. 323, no. 3, pp. 677-696, 2009.

[32] M. Inalpolat and A. Kahraman, "A dynamic model to predict modulation sidebands of a planetary gear set having manufacturing errors," Journal of Sound \& Vibration, vol. 329 , no. 4 , pp. 371-393, 2010.

[33] W. D. Mark and J. A. Hines, "Stationary transducer response to planetary-gear vibration excitation with non-uniform planet loading," Mechanical Systems and Signal Processing, vol. 23, no. 4, pp. 1366-1381, 2009.

[34] J. P. Raclot and P. Velex, "Simulation of the dynamic behaviour of single and multi-stage geared systems with shape deviations and mounting errors by using a spectral method," Journal of Sound \& Vibration, vol. 220, no. 5, pp. 861-903, 1999.

[35] L. Walha, T. Fakhfakh, and M. Haddar, "Nonlinear dynamics of a two-stage gear system with mesh stiffness fluctuation, bearing flexibility and backlash," Mechanism and Machine Theory, vol. 44, no. 5, pp. 1058-1069, 2009.

[36] D. Yassine, H. Ahmed, W. Lassaad, and H. Mohamed, "Effects of gear mesh fluctuation and defaults on the dynamic behavior of two-stage straight bevel system," Mechanism and Machine Theory, vol. 82, no. 24, pp. 71-86, 2014.

[37] K. Dragomiretskiy and D. Zosso, "Variational mode decomposition," IEEE Transactions on Signal Processing, vol. 62, no. 3, pp. 531-544, 2014. 


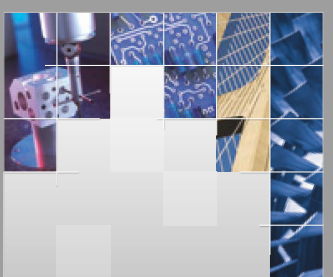

\section{Enfincering}
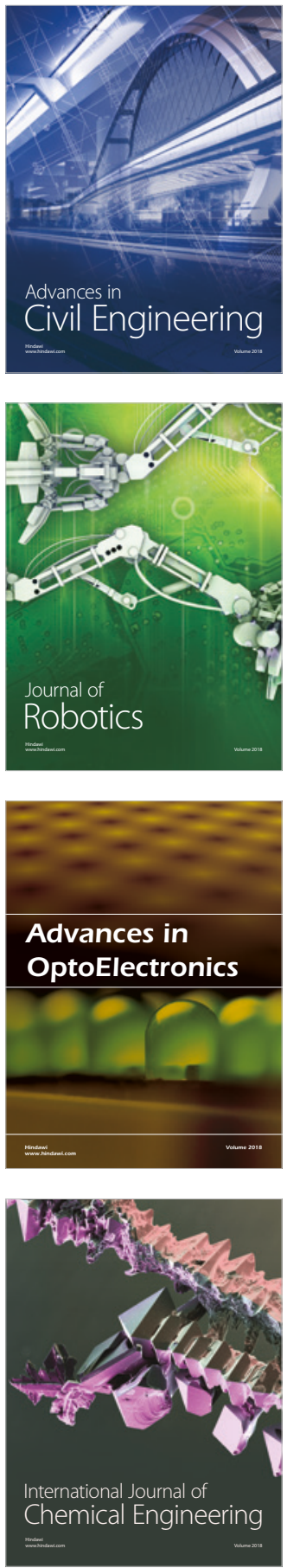

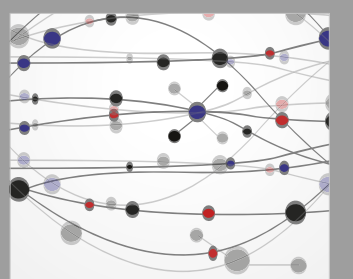

\section{Rotating \\ Machinery}

The Scientific World Journal

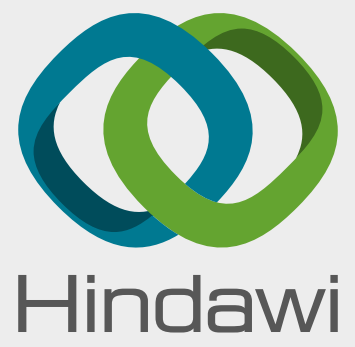

Submit your manuscripts at

www.hindawi.com
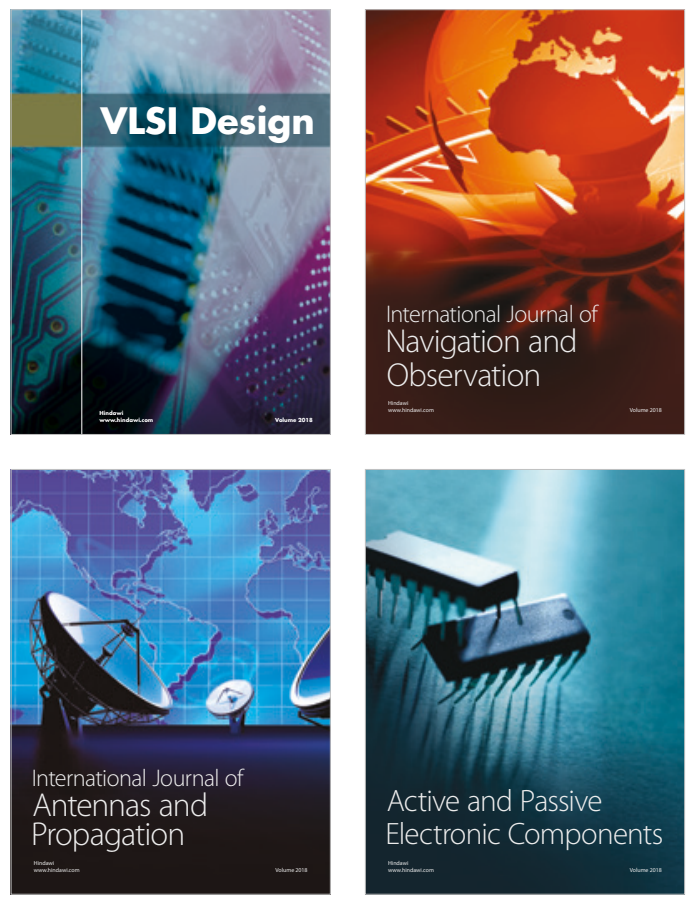
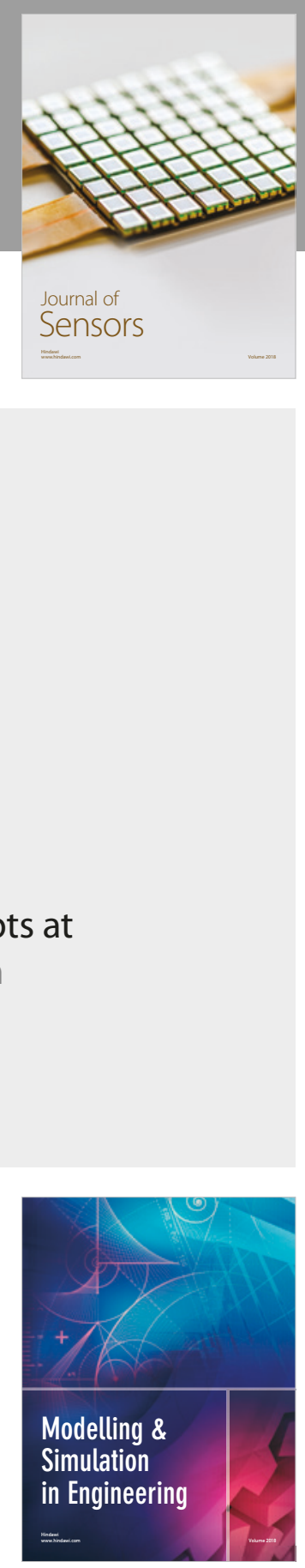

\section{Advances \\ Multimedia}
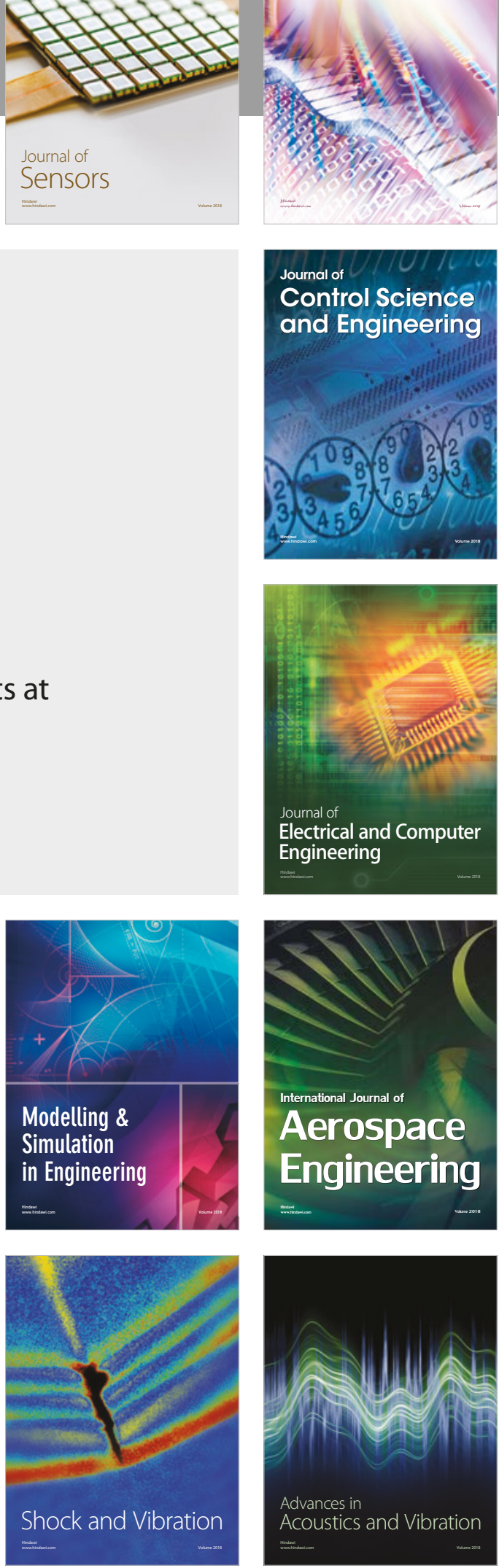